\title{
RESEARCH
}

Open Access

\section{MSC-derived exosomes attenuate cell death through suppressing AIF nucleus translocation and enhance cutaneous wound healing}

Guifang Zhao ${ }^{1,2+}$, Feilin Liư ${ }^{3+}$, Zinan Liu', Kuiyang Zuo ${ }^{1}$, Bo Wang ${ }^{1}$, Yuying Zhang ${ }^{1}$, Xing Han ${ }^{1}$, Aobo Lian ${ }^{1}$, Yuan Wang ${ }^{1}$, Mingsheng Liu', Fei Zou', Pengdong Li', Xiaomei Liu', Minghua Jin ${ }^{1}$ and Jin Yu Liu*

\begin{abstract}
Background: Skin wounding is very common and may be slow to heal. Increasing evidence shows that exosomes derived from mesenchymal stem cells (MSCs) dramatically enhance skin wound healing in a paracrine manner. However, the mechanism underlying this phenomenon has not yet been elucidated. Thus, the objective of the present study was to identify the signaling pathways and paracrine factors by which MSC-derived exosomes promote de novo skin tissue regeneration in response to wound healing.
\end{abstract}

Methods: In vitro and in vivo skin wound healing models were created by treating immortalized human keratinocytes ( $\mathrm{HaCaT})$ with hydrogen peroxide $\left(\mathrm{H}_{2} \mathrm{O}_{2}\right)$ and excising full-thickness mouse skin, respectively. Exosomes were extracted from human umbilical cord Wharton's jelly MSCs (hucMSC-Ex) by ultracentrifugation of cell culture supernatant.

Results: The hucMSC-Ex treatment significantly increased HaCaT cell proliferation and migration in a time- and dose-dependent manner, suppressed $\mathrm{HaCaT}$ apoptosis induced with $\mathrm{H}_{2} \mathrm{O}_{2}$ by inhibiting nuclear translocation of apoptosis-inducing factor (AIF) and upregulating poly ADP ribose polymerase 1 (PARP-1) and poly (ADP-ribose) (PAR). The animal experiments showed that relative to hucMSCs, hucMSC-Ex attenuated full-thickness skin wounding by enhancing epidermal re-epithelialization and dermal angiogenesis.

Conclusions: These findings indicated that direct administration of hucMSC-Ex may effectively treat cutaneous wounding and could be of great value in clinical settings.

Keywords: Apoptosis, Apoptosis-inducing factor, Exosomes, Mesenchymal stem cells, Poly (ADP-ribose) polymerase1, Protease-activated receptor, Skin wound healing

\footnotetext{
* Correspondence: jy_liu@jlu.edu.cn

${ }^{+}$Guifang Zhao and Feilin Liu contributed equally to this work.

'Department of Toxicology, School of Public Health, Jilin University, No. 1163 Xinmin Street, Changchun, Jilin 130021, China

Full list of author information is available at the end of the article
}

C C The Author(s). 2020 Open Access This article is licensed under a Creative Commons Attribution 4.0 International License, which permits use, sharing, adaptation, distribution and reproduction in any medium or format, as long as you give appropriate credit to the original author(s) and the source, provide a link to the Creative Commons licence, and indicate if changes were made. The images or other third party material in this article are included in the article's Creative Commons licence, unless indicated otherwise in a credit line to the material. If material is not included in the article's Creative Commons licence and your intended use is not permitted by statutory regulation or exceeds the permitted use, you will need to obtain permission directly from the copyright holder. To view a copy of this licence, visit http://creativecommons.org/licenses/by/4.0/ The Creative Commons Public Domain Dedication waiver (http://creativecommons.org/publicdomain/zero/1.0/) applies to the data made available in this article, unless otherwise stated in a credit line to the data. 


\section{Background}

The skin is the largest tissue in the body, and its main function is to protect the subcutaneous tissue. Wound healing is a complex process, and successful skin wound healing requires a series of steps, including inflammation, new tissue formation, and remodeling [1]. In addition, the migration, proliferation, differentiation, and apoptosis of skin cells play an important role [2]. The mechanism of poor wound healing in diabetes is not clear, but the causes of this terrible complication mainly include hypoxia, impaired angiogenesis, ROS injury, and neuropathy, resulting in long-term medical burden and decreased quality of life of patient role in this process $[3,4]$.

At present, it is believed that excessive apoptosis of cells with injury repair function, namely, dermal fibroblasts and epidermal keratinocytes, is one of the main reasons for the difficulty in healing or delayed healing of diabetic skin wounds $[5,6]$. Diabetic wounds are characterized by the disorder of the wound healing process, and there is significantly prolonged [7]. The sustained inflammatory response will lead to excessive apoptosis of repair cells, such as fibroblasts, keratinocytes, or vascular endothelial cells, and then cause the wound to be difficult to heal or the healing is delayed $[8,9]$. In the study of the delayed wound healing in diabetic mice, one study found that 7-14 days after the injury in the diabetic mouse wound model, there was significant healing delay compared with the control group, and the apoptosis rate of repair cells around the wound surface was significantly increased and the proliferation rate was significantly decreased [10]. Therefore, by studying the apoptotic forms of basal keratinocytes, we can deeply understand the mechanism of the difficulty in healing or delayed healing of diabetic skin wounds.

Mesenchymal stem cells (MSCs) are a rich, readily accessible source of somatic stem cells. They are easily acquired, highly expanded, and efficiently differentiated into numerous lineages of specialized cells. They are used to engineer functional organs or for in situ tissue repair and regeneration [11]. A previous study [12] showed that MSCs migrate towards tissue injury sites, transdifferentiate into specialized cells, and replace diseased, lost, aged, or apoptotic cells. Recent research has demonstrated that the rates of trans-differentiation of MSCs to specialized cells and their engraftment in injured tissues are too low to effect substantial repair and regeneration [13]. Therefore, it has become an important issue in regenerative medicine research to find new biological products or materials that can replace MSCs and clarify their regeneration and repair function and mechanism.

Exosomes are nanoscale microvesicles sprouting from various types of cells by the budding way [14]. The exosomes encapsulate nucleic acids, proteins, and lipids from the donor cells. When they are released, exosomes deliver these bioactive molecules to recipient cells such as resting stem cells in the stem cell niche or injured cells in the traumatic microenvironment $[15,16]$. They then induce regeneration by activating resting stem cells or recovering the functionality of the injured cells. Exosomes have functional tissue repair and regeneration properties resembling those of the cells from which they are derived [17]. They induce none of the apparent adverse effects associated with stem cell implantation such as immunogenicity [18], malignant transformation [19, $20]$, or vascular obstruction [21, 22]. Thus, exosomebased therapy may be safer, easier, and more efficient for tissue repair and regeneration than stem cell-based therapy. Localized injections of exosomes originating from mesenchymal stem cells may promote skin cell proliferation and migration and angiogenesis via the wnt 4 pathway or Erk $1 / 2$ signaling in animal burn or diabetic wound models [23]. Therefore, exosome-based therapy could be a promising approach to wound healing. Our group showed that direct administration of human umbilical cord mesenchymal stem cells (hucMSCs) into full-thickness skin defects of immunocompetent mice significantly enhanced cutaneous wound healing. However, transplantation of human cells into mice is xenografting, and the implanted cells were inevitably rejected by the host immune response. For this reason, hucMSCs-initiated paracrine factors play predominant roles in cutaneous wound healing. However, the mechanism by which they enhance skin wound healing remains to be elucidated [24].

To this end, we created cellular and animal models of skin defects by treating the $\mathrm{HaCaT}$ epidermal cell line with hydrogen peroxide $\left(\mathrm{H}_{2} \mathrm{O}_{2}\right)$ and by excising fullthickness skin from the backs of $\mathrm{C} 57$ mice, respectively. We isolated exosomes from hucMSCs (hucMSCs-Ex) by ultracentrifugation and compared them with hucMSCsconditioned medium (hucMSCs-CM), exosome-free hucMSCs-CM (hucMSCs-dp-Ex), and hucMSCs in terms of skin wound healing efficacy. Our results showed that hucMSCs-Ex significantly inhibited the nuclear translocation of apoptosis-inducing factor (AIF), the activation of poly (ADP-ribose) polymerase-1 (PARP1), and the induction of $\mathrm{HaCaT}$ cell apoptosis by $\mathrm{H}_{2} \mathrm{O}_{2}$. It also enhanced cutaneous wound healing in fullthickness skin defect animal models as did hucMSCs and hucMSCs-CM.In this study, we hypothesized that hucMSCs-Ex can promote cutaneous wound healing via the PARP-1/AIF apoptosis pathway.

\section{Methods}

Derivation of hucMSCs from human umbilical cord Wharton's jelly

The present study was approved by the Ethics Committee of the School of Public Health, Jilin University, Jilin, 
China. The umbilical cords were obtained from healthy patients at the Affiliated Hospital of Jilin University. The donors had granted prior informed written consent. The isolation, phenotype characterization, and multipotency assay of mesenchymal stem cells (hucMSCs) from umbilical cord Wharton's jelly were performed as previously described [24]. Briefly, hucMSCs were obtained by organ harvest and cultured in Dulbecco's modified Eagle's medium (DMEM, high-glucose; Invitrogen, Carlsbad, CA, USA) containing $10 \%(\mathrm{w} / \mathrm{v})$ fetal bovine serum (FBS; HyClone, Melbourne, Australia), $100 \mathrm{U} \mathrm{mL}^{-1}$ penicillin/ streptomycin (Sigma, Munich, Germany) and $10 \mathrm{ng}$ $\mathrm{mL}^{-1}$ basic fibroblast growth factor (bFGF; Peprotech, London, UK) at $37^{\circ} \mathrm{C}$ under a $5 \% \mathrm{CO}_{2}$ atmosphere. Immunofluorescence staining and flow cytometry were performed on hucMSCs to evaluate the expression levels of the surface markers CD34, CD45, CD44, CD73, CD90, and CD105 (BD Biosciences, Franklin Lakes, NJ, USA). For the multipotency assay, the hucMSCs were cultured in adipogenic medium consisting of DMEM, 10\% (w/v) FBS, $1 \mu \mathrm{M}$ dexamethasone (Sigma-Aldrich Corp., St Louis, MO, USA), $0.5 \mathrm{mM}$ isobuty1 methylxanthine (Sigma-Aldrich Corp., St Louis, MO, USA), $200 \mu \mathrm{M}$ indomethacin (Sigma-Aldrich Corp., St Louis, MO, USA), and $10 \mu \mathrm{M}$ insulin (Sigma-Aldrich Corp., St Louis, MO, USA) in osteogenic medium consisting of DMEM, $10 \%(w / v)$ FBS, $10 \mathrm{mM} \beta$-glycerophosphate (Alfa Aesar, Ward Hill, MA, USA), $0.1 \mu \mathrm{M}$ dexamethasone, and $50 \mu \mathrm{M}$ ascorbate-2-phosphate (Sigma-Aldrich Corp., St Louis, MO, USA) and chondrogenic medium consisting of DMEM, $10 \%(\mathrm{w} / \mathrm{v}) \mathrm{FBS}, 6.25 \mu \mathrm{g} \mathrm{mL}^{-1}$ insulin, $10 \mathrm{ng}$ $\mathrm{mL}^{-1}$ transforming growth factor-beta 1 (PeproTech, London, UK), and $50 \mathrm{nM}$ ascorbate-2-phosphate (SigmaAldrich Corp., St Louis, MO, USA). Three weeks after adipogenic, osteogenic, and chondrogenic induction, intracellular lipid droplets, mineralized bone nodules, and sulfated proteoglycans were detected by Oil Red O staining, Alizarin Red-S staining, and Alcian Blue staining (Dingguo, Beijing, China) according to the manufacturers' instructions.

\section{Derivation, labeling, and uptake assays of hucMSCs-Ex}

Exosome isolation from MSCs was described elsewhere [25]. Briefly, hucMSCs at passage 4 were cultivated in DMEM containing $10 \mathrm{ng} \mathrm{mL}^{-1} \mathrm{bFGF}$ and $10 \%(\mathrm{w} / \mathrm{v})$ FBS deprived of exosomes by centrifugation at $120,000 \times g$ overnight at $4{ }^{\circ} \mathrm{C}$. When the hucMScs reached $80 \%$ confluency, they were cultivated in DMEM containing $2 \%$ $(\mathrm{w} / \mathrm{v})$ exosome-free fetal bovine serum (FBS) for $24 \mathrm{~h}$. The culture medium was then collected and centrifuged at $300 \times g$ at $4{ }^{\circ} \mathrm{C}$ for $10 \mathrm{~min}$ to pelletize the cells. The supernatant was collected, centrifuged at $16,500 \times g$ (Optima $^{\text {TM }}$ L-100XP ultracentrifuge; Beckman Coulter, Palo Alto, CA, USA) at $4{ }^{\circ} \mathrm{C}$ for $20 \mathrm{~min}$ then passed through a $0.22-\mu \mathrm{m}$ filter to remove cell debris. This medium was designated conditioned medium (hucMSCs-CM). The filtrate was centrifuged at $120,000 \times g$ at $4{ }^{\circ} \mathrm{C}$ for $90 \mathrm{~min}$. The exosomes were collected and designated hucMSCsderived exosomes (hucMSCs-Ex). The hucMSCs-Ex were resuspended in phosphate-buffered saline (PBS) and stored at $-80^{\circ} \mathrm{C}$. The protein concentration in the hucMSCs-Ex was measured with bovine calf albumin (BCA) kit (Beyotime, Shanghai, China). The size distribution and concentration of exosomes were analyzed by nanoparticle tracking analysis using a ZetaView particle tracker from ParticleMetrix (Germany), Each NTA measurement for the different protocols for each subject was repeated in triplicate. The morphology of the hucMSCs-Ex was examined by transmission electron microscopy (TEM; FEI Tecnai 12; Philips, Amsterdam, The Netherlands). The expression levels of CD9 and CD63 (1: 500, Millipore, Temecula, CA, USA) and Alix (1:1000, Abcam, USA) and TSG101 (1:500, ProteinTech, Chicago, USA) and HSP70 (1:500, SCB, USA, in the exosomes were determined by western blot assay. The exosome-free medium was designated exosomes-deprived hucMSCsconditioned media (hucMSCs-dp-Ex).

The hucMSCs-Ex were labeled with PKH26 (SigmaAldrich Corp., St. Louis, MO, USA) as previously described [26]. In brief, $2 \mu \mathrm{L}$ PKH26 was mixed with $1 \mathrm{~mL}$ hucMSCs-Ex $\left(1 \mu \mathrm{g} \mathrm{mL}^{-1}\right)$ and incubated at room temperature $\left(20-25^{\circ} \mathrm{C}\right)$ for $25 \mathrm{~min}$. Then, $1 \mathrm{~mL}$ of $1 \%$ $(\mathrm{w} / \mathrm{v})$ bovine serum albumin (BSA; Roche Diagnostics, Mannheim, Germany) was added to the incubation mixture to terminate labeling. PKH26-labeled hucMSCs-Ex were collected by centrifugation at $100,000 \times g$ at $4{ }^{\circ} \mathrm{C}$ for $2 \mathrm{~h}$, washed by PBS for once, then used as a supplement in the $\mathrm{HaCaT}$ cell culture. The $\mathrm{HaCaT}$ cells were cultured with PKH26-labeled hucMSCs-Ex for $24 \mathrm{~h}$, fixed with $4 \%(\mathrm{w} / \mathrm{v})$ paraformaldehyde, counterstained with Hoechst 33342 (Invitrogen, Carlsbad, CA, USA), observed under a fluorescence microscope (4000B; Leica Microsystems, Wetzlar, Germany), and photographed with a microscope-mounted digital camera (DFC500; Leica Microsystems, Wetzlar, Germany).

\section{Cell viability, apoptosis assays, and ROS detection}

Immortalized epidermal $\mathrm{HaCaT}$ cells were purchased from Peking Union Medical College Hospital, Beijing, China, and cultured in DMEM supplemented with $10 \%$ (w/v) FBS (HyClone, Thermo Fisher Scientific, Melbourne, Australia) and $100 \mathrm{U} \mathrm{mL}^{-1}$ penicillin/streptomycin (Sigma-Aldrich Corp., St. Louis, MO, USA) at $37^{\circ} \mathrm{C}$ under a $5 \% \mathrm{CO}_{2}$ atmosphere. For the cell viability, ROS generation, and apoptosis assays, the $\mathrm{HaCaT}$ cells were seeded into 96- or 6-well tissue culture plates in triplicate at a density of $5 \times 10^{4} \mathrm{~cm}^{-2}$ and cultured for $24 \mathrm{~h}$ in DMEM supplemented with $10 \%(\mathrm{w} / \mathrm{v}) \mathrm{FBS}$. The 
culture medium was then aspirated and the cells were washed with PBS and cultured in DMEM containing 2\% (w/v) FBS with or without $\mathrm{H}_{2} \mathrm{O}_{2}$ at a final concentration of $1 \mathrm{mM}$ for another $0.5 \mathrm{~h}, 1 \mathrm{~h}, 2 \mathrm{~h}, 4 \mathrm{~h}$, and $6 \mathrm{~h}$. Then CCK8 (Dojindo Molecular Technologies, Tokyo, Japan), reactive oxygen species (ROS) (Millipore EMD, Billerica, MA, USA), propidium iodine-Annexin V (San Jian, Tianjin, China), and TUNEL (Promega, Madison, WI, USA) staining were performed to measure cell viability, ROS generation, and apoptosis at the indicated time points according to the manufacturers' instructions.

$\mathrm{HaCaT}$ cells were seeded in a 24-well plate at a density of $5 \times 10^{4} \mathrm{~cm}^{-2}$ and cultured overnight in DMEM containing 10\% (w/v) FBS. Next day, the culture medium was aspirated and the cells were washed thrice in PBS and cultured in DMEM containing $2 \%(\mathrm{w} / \mathrm{v})$ exosomedeprived FBS and $1 \mathrm{mM} \mathrm{H}_{2} \mathrm{O}_{2}$ with the PARP-1 inhibitor 3,4-dihydro-5-[4-(1-piperidinyl)butoxy]-1(2H)-isoquinolinone (DPQ) (MedChemExpress, Monmouth Junction, NJ, USA) or the broad-spectrum caspase inhibitor Z-VAD.fmk (Santa Cruz Biotechnology, Dallas, TX, USA) at the indicated dosages or at $1000 \mathrm{ng} \mathrm{m}^{-1}$ hucMSCs-Ex for $4 \mathrm{~h}$. Then propidium iodine-Annexin $\mathrm{V}$ staining and flow cytometry were performed to detect $\mathrm{HaCaT}$ cell apoptosis.

\section{Cell proliferation and migration assay}

$\mathrm{HaCaT}$ cells were seeded in a 96-well plate at a density of $5 \times 10^{4} \mathrm{~cm}^{-2}$ and cultured overnight in DMEM containing $10 \%(\mathrm{w} / \mathrm{v})$ FBS. The next day, the culture medium was aspirated and the cells were washed thrice in PBS and cultured for $4 \mathrm{~h}$ in DMEM containing $2 \%$ (w/v) exosome-free FBS with or without $1 \mathrm{mM} \mathrm{H}_{2} \mathrm{O}_{2}$. The cells were then washed thrice in PBS and cultured for another $24 \mathrm{~h}$ in DMEM containing 2\% (w/v) exosome-free FBS (control), hucMSCs-CM, hucMSCs$\mathrm{dp}-\mathrm{Ex}$, or hucMSCs-Ex at the indicated concentrations or time points. Then, a CCK8 assay was run to detect $\mathrm{HaCaT}$ proliferation under the aforementioned culture conditions.

Transwell and cell scratching assays were implemented to determine cell migration. Briefly, $\mathrm{HaCaT}$ cells were seeded in the upper chamber of a Transwell $(8-\mu \mathrm{m}$ pore filters; Corning, Corning, NY, USA) according to the manufacturer's instructions. The $\mathrm{HaCaT}$ cells were also seeded in 6-well plates at a density of $5 \times 10^{4} \mathrm{~cm}^{-2}$ and cultured overnight in DMEM containing 10\% (w/v) FBS. The next day, the cells were washed thrice in PBS and cultured for $4 \mathrm{~h}$ in DMEM containing $2 \%(\mathrm{w} / \mathrm{v})$ exosome-free FBS with or without $1 \mathrm{mM} \mathrm{H}_{2} \mathrm{O}_{2}$. Then, the $\mathrm{HaCaT}$ cells cultured in the 6-well plates were scratched with a $200-\mu \mathrm{L}$ micropipette tip. The $\mathrm{HaCaT}$ cells cultured in the Transwell and 6-well plates were washed thrice in PBS and cultured for $24 \mathrm{~h}$ in DMEM containing $2 \%(\mathrm{w} / \mathrm{v})$ exosome-deprived FBS, hucMSCsCM, hucMSCs-dp-Ex, or hucMSCs-Ex in 6-well plates or in $100 \mu \mathrm{L}$ DMEM containing $2 \%$ (w/v) exosomedeprived FBS in the upper Transwell chamber. The lower Transwell chamber was filled with $600 \mu \mathrm{L}$ DMEM containing $2 \%$ exosome-free FBS, hucMSCs-CM, hucMSC-dp-Ex, and $1000 \mu \mathrm{g}$ hucMSCs-Ex for $24 \mathrm{~h}$. Then, the Transwells were removed from the tissue culture plate, the culture medium in the upper Transwell chamber was aspirated, and the $\mathrm{HaCaT}$ cells in the Transwells were fixed with methanol, dried under a laminar flow hood, and stained with Hoechst 33342 (1:10, 000, RT, 2 min; Life Technologies, Carlsbad, CA, USA). A cotton tab was used to remove the $\mathrm{HaCaT}$ cells retained in the upper Transwell chamber and the cells were washed thrice in PBS. The $\mathrm{HaCaT}$ cells retained in the lower Transwell chamber were photographed under a fluorescent microscope (Olympus, Tokyo, Japan). The HaCaT cells in five randomly selected view fields were analyzed by Image software $(\mathrm{NIH}$, Bethesda, MD, USA). The HaCaT cells cultured in 6well plates were photographed. ImageJ was used to measure their migration under the aforementioned culture conditions. Migration rates were calculated as follows: (distance of cells at scratching time point -distance of cells $24 \mathrm{~h}$ post-scratching)/(distance of cells at scratching time point).

\section{Protein extraction and western blot assay}

$\mathrm{HaCaT}$ cells were seeded in tissue culture plates at a density of $5 \times 10^{4} \mathrm{~cm}^{-2}$ and cultured overnight in DMEM containing 10\% (w/v) FBS. Next day, the cells were washed thrice in PBS and cultured in DMEM containing $2 \%(\mathrm{w} / \mathrm{v})$ exosome-free FBS with or without 1 $\mathrm{mM} \mathrm{H}_{2} \mathrm{O}_{2}$ for the indicated time intervals. Then the $\mathrm{HaCaT}$ cells were washed thrice in PBS and either harvested by trypsin digestion and centrifugation or left for another $24 \mathrm{~h}$ in DMEM containing 2\% (w/v) exosomefree FBS, hucMSCs-CM, hucMSCs-dp-Ex, or hucMSCs$\mathrm{Ex}$ at the indicated concentrations. Then, the $\mathrm{HaCaT}$ cells were washed twice in cold PBS and harvested by trypsin digestion as described above. Total, cytoplasmic, nuclear, and mitochondrial proteins from the $\mathrm{HaCaT}$ cells were extracted using kits (Keygentec, Nanjing, China) according to the manufacturer's instructions. Briefly, the $\mathrm{HaCaT}$ cells were lysed by ultrasound in icecold radioimmunoprecipitation assay (RIPA) buffer containing $1 \mathrm{mM}$ phenylmethylsulfonyl fluoride (PMSF) (Beyotime Biotechnology, Jiangsu, China) on ice. The lysates were centrifuged at $12,000 \times g$ for $20 \mathrm{~min}$ at $4{ }^{\circ} \mathrm{C}$. The supernatants contained the total protein. For cytoplasmic and nuclear protein extraction, the $\mathrm{HaCaT}$ cells were resuspended in protein extraction buffer A $[10 \mathrm{mM}$ HEPES (pH 7.4), $1.5 \mathrm{mM} \mathrm{MgCl}_{2}, 10 \mathrm{mM} \mathrm{KCl}, 0.5 \mathrm{mM}$ 
DTT, and 0.1\% (w/v) NP-40] then buffer B was added and cell lysates were centrifuged at $16,000 \times g$ and $4{ }^{\circ} \mathrm{C}$ for $5 \mathrm{~min}$. The supernatant was collected, an equal volume of buffer $\mathrm{C}$ was added to it, and the mixture was centrifuged at $15,000 \times g$ for $10 \mathrm{~min}$ at $4{ }^{\circ} \mathrm{C}$. The supernatant was collected and designated the cytoplasmic protein. The nuclear pellet was washed with buffer A, resuspended in buffer $\mathrm{C}$ [20 mM HEPES (pH 7.9), 1.5 $\mathrm{mM} \mathrm{MgCl} 2,0.5 \mathrm{mM}$ dithiothreitol (DTT), 25\% (w/v) glycerol, $0.5 \mathrm{mM}$ PMSF, $0.2 \mathrm{mM}$ EDTA, and $420 \mathrm{mM}$ $\mathrm{NaCl}$, and centrifuged at $16,000 \times g$ for $10 \mathrm{~min}$ at $4{ }^{\circ} \mathrm{C}$. The supernatant was then isolated. For mitochondrial protein separation, the post-centrifugation cytoplasm fraction was transferred to a new tube and the mitochondrion pellet was resuspended in buffer D (20\% (w/ v) glycerol, $20 \mathrm{mM}$ HEPES, $10 \mathrm{mM} \mathrm{KCl}, 1.5 \mathrm{mM} \mathrm{MgCl}$, $1 \mathrm{mM}$ EDTA, $1 \mathrm{mM}$ EGTA, $1 \mathrm{mM}$ DTT, $0.5 \mathrm{mM}$ PMSF, $8 \mu \mathrm{g} / \mathrm{mL}$ aprotinin, $2 \mu \mathrm{g} / \mathrm{mL}$ leupeptin) and centrifuged at $15,000 \times g$ for $10 \mathrm{~min}$ at $4{ }^{\circ} \mathrm{C}$. The pellet contained the mitochondrial protein.

\section{Cell viability, apoptosis assays, and ROS detection}

Equal amounts of protein were separated by sodium dodecyl sulfate-polyacrylamide gel electrophoresis (SDSPAGE) and electronically transferred to a polyvinylidene fluoride (PVDF) membrane (Millipore EMD, Billerica, MA, USA). The membranes were blocked in $5 \%(\mathrm{w} / \mathrm{v})$ non-fat milk at room temperature for $1 \mathrm{~h}$ and incubated overnight at $4{ }^{\circ} \mathrm{C}$ with the antibodies listed in Table 1 . After being washed three times in TBST (Tris-buffered saline with Tween-20), the membranes were incubated with the appropriate horseradish peroxidase-conjugated secondary antibodies for $1 \mathrm{~h}$ at room temperature then with ECL (enhanced chemiluminescence) reagent (Beyotime Biotechnology, Jiangsu, China). Proteins were

Table 1 List of antibodies used for Western blott assay

\begin{tabular}{llll}
\hline Antibody & Antibody dilution & Supplier & Catalog number \\
\hline AIF & $1: 1000$ & CST $^{*}$ & $4542 \mathrm{~s}$ \\
PARP-1 & $1: 1000$ & CST & $9532 \mathrm{~s}$ \\
PAR & $2.5 \mu \mathrm{g} \mathrm{m}^{-1}$ & IBL** & $1 \mathrm{C}-205$ \\
Calpain I & $1: 1000$ & CST & $2556 \mathrm{~s}$ \\
Cytochrome C & $1: 1000$ & CST & $4280 \mathrm{~s}$ \\
CypA & $1: 200$ & SCB*** & SC-133494 \\
Hsp70 & $1: 500$ & SCB & SC-1060 \\
Caspase-3 & $1: 1000$ & CST & $9664 \mathrm{~s}$ \\
$\beta$-actin & $1: 3000$ & SunGene**** & Km-9001 \\
Histon3.1 & $1: 3000$ & SunGene & Km-9005 \\
COX IV & $1: 3000$ & CST & 48445
\end{tabular}

*Cell Signaling Technology, Danvers, MA, USA

**Immuno-Biological Laboratories, Fujioka, Japan

**Santa Cruz Biotechnology, Dallas, TX, USA

****SunGene GmbH, Gatersleben, Germany detected with a GENE GNOME (Gene Company Ltd., Hong Kong, China). Gray intensities were measured with GeneTools software (Syngene, Frederick, MD, USA).

\section{Immunofluorescence staining}

Immunofluorescence staining was performed on $\mathrm{HaCaT}$ cells as previously described [24]. Briefly, $\mathrm{HaCaT}$ cells were cultured in DMEM containing 10\% (w/v) FBS in 24-well tissue culture plates. When the cells reached $70 \%$ confluence, they were incubated for $4 \mathrm{~h}$ in DMEM containing $2 \%(\mathrm{w} / \mathrm{v})$ exosome-free FBS with or without $1 \mathrm{mM} \mathrm{H}_{2} \mathrm{O}_{2}$. Alternatively, the $\mathrm{HaCaT}$ cells were pretreated for $1 \mathrm{~h}$ with DPQ $\left(30 \mu \mathrm{M} \mathrm{mL}^{-1}\right)$ and Z-VAD.fmk $\left(100 \mu \mathrm{M} \mathrm{mL}^{-1}\right)$ or hucMSCs-CM, hucMSCs-dp-Ex, and hucMSCs-Ex then cultured with $1 \mathrm{mM} \mathrm{H}_{2} \mathrm{O}_{2}$ for another $4 \mathrm{~h}$. The cells were then washed twice in PBS, fixed in $4 \%(\mathrm{w} / \mathrm{v})$ PFA/PBS, and permeabilized in $1 \%(\mathrm{w} / \mathrm{v})$ Triton X-100 followed by incubation with anti-PAR, antiAIF, and anti-cyt $\mathrm{C}$ antibodies (Table 1) overnight at $4{ }^{\circ} \mathrm{C}$. The cells were then washed and incubated with Alexa Fluor 546-conjugated donkey anti-goat IgG (1:800 dilution; Invitrogen, Carlsbad, CA, USA) or Alexa Fluor 488-conjugated anti-mouse IgG (1:400 dilution; Cell Signaling Technology, Danvers, MA, USA) at room temperature for $1 \mathrm{~h}$. The cells were then extensively washed in PBS, counterstained with Hoechst 33342 (1: 10,000, RT, 2 min; Life Technologies, Carlsbad, CA, USA) and observed under a fluorescence microscope (DMI4000B; Leica Microsystems, Wetzlar, Germany) and photographed with a microscope-mounted digital camera (DFC500; Leica Microsystems, Wetzlar, Germany). The percentage of positive cells in five random view fields was evaluated with Image software (NIH, Bethesda, MD, USA).

\section{Full-thickness skin defects and mouse cutaneous wound healing}

All animal experiments were conducted in compliance with the guidelines approved by the China Association of Laboratory Animal Care and the Institutional Animal Care Committee. Balb/C mice (male; 20-25 g) were purchased from Fukang Animal Breeding Center, Beijing, China, and maintained at the Institutional Animal Center of Jilin University, Jilin, China. The mice were acclimated to their environment for 1 week. After acclimation, a fullthickness excisional wound $(0.8 \mathrm{~cm} \times 0.8 \mathrm{~cm})$ was made with surgical scissors on the dorsal skin of each mouse. The mice were randomly divided into six groups, each of which comprised 10 mice. The corners of each wound margin were subcutaneously injected with $10^{6}$ hucMSCs $100 \mu \mathrm{L}^{-1}$ PBS (hucMSCs group), $100 \mu \mathrm{g}$ hucMSCs-Ex $100 \mu \mathrm{L}^{-1}$ PBS (hucMSCs-Ex group), $100 \mu \mathrm{L}$ PBS (PBS group); $100 \mu \mathrm{L}$ hucMSCs-CM (hucMSCs-CM group), $100 \mu \mathrm{L}$ hucMSC-dp-Ex (hucMSCs-dp-Ex group), or 
nothing (sham group). The wounds were wrapped with a single layer of oil gauze covered by three layers of cotton gauze as previously described.

\section{Gross inspection and H\&E and immunofluorescence staining}

At days 7 and 14 after wounding, photographs of the wound sites were taken for gross inspection of wound closure. The outline along the wound margin was depicted with transparent film and the wound closure rate was calculated as follows:

((original wound area-new wound area)/original wound area) $\times 100$.

The mice were sacrificed by anesthetic overdose and skin specimens including wounds and neighboring tissues were collected, fixed with $10 \%(\mathrm{w} / \mathrm{v})$ buffered formaldehyde/PBS, embedded in paraffin, sectioned at a $5-\mu \mathrm{m}$ thickness in the center of the wound, and stained with hematoxylin and eosin $(\mathrm{H} \& \mathrm{E})$. The tissue sections were observed and photographed under a microscope. Epidermal tissue subtended by hair follicle-free dermis was designated newly formed epidermis. The histological wound healing rate was calculated as follows:

(length of newly formed epidermis)/(length of newly formed epidermis + non-healed epidermis)

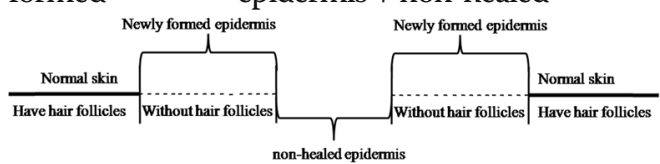

Immunofluorescence staining was performed to detect epidermal formation, dermal angiogenesis, and scar tissue in the wounded skin. Briefly, skin section slides were deparaffinized, rehydrated, and blocked in $1 \%(\mathrm{w} / \mathrm{v})$ BSA/PBS at room temperature for $30 \mathrm{~min}$. The slides were incubated with rat anti-mouse primary antibody against CD31 (1:100; Cell Signaling Technology, Danvers, MA, USA), cytokeratin 10 (1: 100; Abcam, Cambridge, MA, USA), or $\alpha$-SMA (1: 200; Cell Signaling Technology, Danvers, MA, USA) at $4{ }^{\circ} \mathrm{C}$ overnight then washed thrice in PBS. The slides were incubated with Alexa Fluor-488/555-conjugated anti-mouse secondary antibody at room temperature for $30 \mathrm{~min}$ and counterstained with Hoechst 33342 (Invitrogen, Carlsbad, CA, USA) to track the nuclei. The slides were observed and photographed under a fluorescence microscope fitted with a digital camera (Leica, DFC500, Wetzlar, Germany). Five randomly selected fields per tissue section were observed at $\times 400$. Three sections were chosen from three mice per group. Image-Pro Plus (Media Cybernetics, Rockville, MD, USA) was used to determine the average optical densities for CD31 and $\alpha$-SMA expression. Five randomly selected fields were examined per group at each time point and used to calculate the average optical density per unit area.

\section{Statistical analysis}

Statistical analysis was performed using SPSS v. 17.0 (IBM Corp., Armonk, NY, USA). Data are means \pm standard deviation (SD) for $\geq 3$ independent experiments. Multiple group comparisons were made by oneway ANOVA. Paired group comparisons were made with Student's $t$ test. $P<0.05$ was considered statistically significant.

\section{Results}

\section{Derivation of exosomes from hucMSCs}

HucMSCs were obtained from the culture of human Wharton's jelly tissues. They were spindle-shaped and highly expressed the MSC surface markers CD44, CD73, CD90, and CD105 (Fig. 1a, b). Under the appropriate culture conditions, they differentiated into adipocytes, osteoblasts, and chondrocytes as indicated by intracellular lipid droplet formation (Oil Red O staining), mineralized bone nodules (Alizarin Red-S staining), and sulfated proteoglycans (Alcian Blue staining), respectively (Fig. 1c). The exosomes were derived from hucMSC culture containing $2 \%(\mathrm{w} / \mathrm{v})$ exosome-deprived FBS by ultracentrifugation. TEM revealed that the vesicles from hucMSCs with characteristic cup-shaped morphology were observed (Fig. 1d). The presence of exosomal marker proteins CD9, CD63, Alix, TSG101, and HSP70 was detected by Western blot (Fig. 1e). The particle size distribution of vesicles displayed about $85 \%$ range from 20 to $200 \mathrm{~nm}$ by nanoparticle tracking analysis (Fig. 1f).

To detect hucMSC-Ex internalization by $\mathrm{HaCaT}$, hucMSC-Ex was labeled with the fluorescent dye PHK26. The PKH26-labeled exosomes were incubated with $\mathrm{HaCaT}$ cells. Within $24 \mathrm{~h}$, the fluorescent label was detected under the fluorescence microscope in the cytoplasms and nuclei of the $\mathrm{HaCaT}$ cells. Thus, the hucMSc-Ex was absorbed into the $\mathrm{HaCaT}$ cytoplasms and nuclei (Fig. 1g).

\section{Establishment of HaCaT apoptosis model induced by $\mathrm{H}_{2} \mathrm{O}_{2}$}

To generate a skin cell damage model, $\mathrm{HaCaT}$ cells were treated with $1 \mathrm{mM} \mathrm{H}_{2} \mathrm{O}_{2}$ for $\leq 6.0 \mathrm{~h}$. Phase-contrast microscopy showed that over time the $\mathrm{HaCaT}$ cell morphology changed from cobblestone to polygonal and the cells detached from the tissue culture plates (Fig. 2a). The CCK8 assay showed that $\mathrm{HaCaT}$ cell viability markedly decreased in a time-dependent manner from $100 \%$ to $43.56 \pm 2.73 \%$ after $4 \mathrm{~h}(P<0.01)$ and $26.7 \pm 3.08 \%$ after $6 \mathrm{~h}(P<0.01)$ following treatment with $1 \mathrm{mM} \mathrm{H}_{2} \mathrm{O}_{2}$ (Fig. 2b).

Consistent with the CCK8 assay, Annexin V-PI staining combined with flow cytometry assay showed that the proportions of cells increased with time from $5.68 \pm$ $0.87 \%$ at time 0 to $29.75 \pm 2.8 \%$ at $4 \mathrm{~h}\left(\mathrm{AV}^{+}\right.$and $\mathrm{PI}^{+}$; 


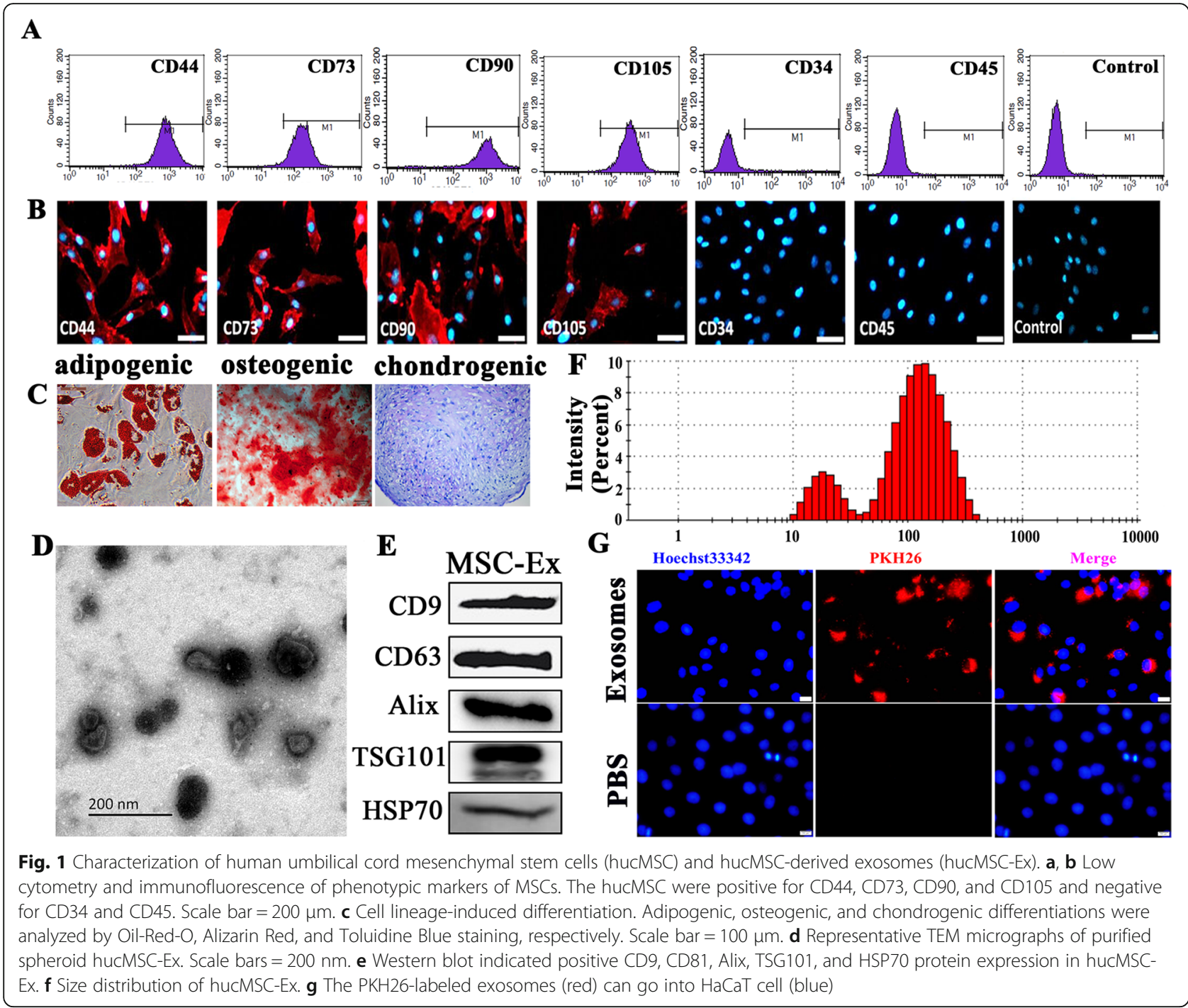

$P<0.01)$ and from $3.32 \pm 0.86 \%$ at time 0 to $21.23 \pm 2.84 \%$ at $4 \mathrm{~h}\left(\mathrm{AV}^{+} / \mathrm{PI}^{-} ; P<0.01\right)$ (Fig. $\left.2 \mathrm{c}, \mathrm{d}\right)$. These values were significantly higher than those for the control group.

Flow cytometry disclosed that the ROS fluorescence intensity increased with time from $674.39 \pm 78.3$ at time 0 to $2750.62 \pm 77.6$ at $4 \mathrm{~h}(P<0.01)$ (Fig. $2 \mathrm{e}, \mathrm{f})$.

\section{$\mathrm{H}_{2} \mathrm{O}_{2}$-induced $\mathrm{HaCaT}$ cell death involved spatiotemporally} dependent, and caspase-dependent- and caspase-

independent cell death

$\mathrm{H}_{2} \mathrm{O}_{2}$-induced cell death is mitochondrial-mediated apoptosis. Caspase-dependent- and caspase-independent cell death participate in mitochondrial cell death. To determine which type of cell death affects $\mathrm{H}_{2} \mathrm{O}_{2}$-treated $\mathrm{HaCaT}$ cells, we measured the expression levels of the proteins associated with mitochondrial-mediated caspase-dependentand caspase-independent cell death. After $\mathrm{H}_{2} \mathrm{O}_{2}$ treatment, expression of apoptosis-inducing factor (AIF) and cytochrome $\mathrm{C}$ significantly decreased in $\mathrm{HaCaT}$ cell mitochondria over time $(P<0.01)$ (Fig. 3a, b). AIF, cleaved PARP-1, and CypA were significantly upregulated in the $\mathrm{HaCaT}$ cell nuclei over time (Fig. 3c, d). Cytochrome C and cleaved caspase-3 increased in the cytosolic fraction whereas HSP70 dramatically decreased there over time (Fig. 3e-g). A whole-cell lysate assay showed that PAR accumulated in $\mathrm{H}_{2} \mathrm{O}_{2}$-treated $\mathrm{HaCaT}$ cells over time (Fig. $3 \mathrm{~h}$, i). The aforementioned data suggest that $\mathrm{H}_{2} \mathrm{O}_{2}$-induced $\mathrm{HaCaT}$ cell death is mitochondrially mediated and participates in caspase-dependent- and caspase-independent apoptosis. Caspase-independent cell death occurred earlier than caspase-dependent cell death.

AIF nuclear translocation and PARP-1 activation are the predominant causes of $\mathrm{H}_{2} \mathrm{O}_{2}$-induced $\mathrm{HaCaT}$ cell death To determine which type of apoptosis plays a predominant role in $\mathrm{H}_{2} \mathrm{O}_{2}$-induced $\mathrm{HaCaT}$ cell death, we pretreated $\mathrm{HaCaT}$ cells with the broad-spectrum caspase inhibitor Z-VAD.fmk and the PARP-specific inhibitor 

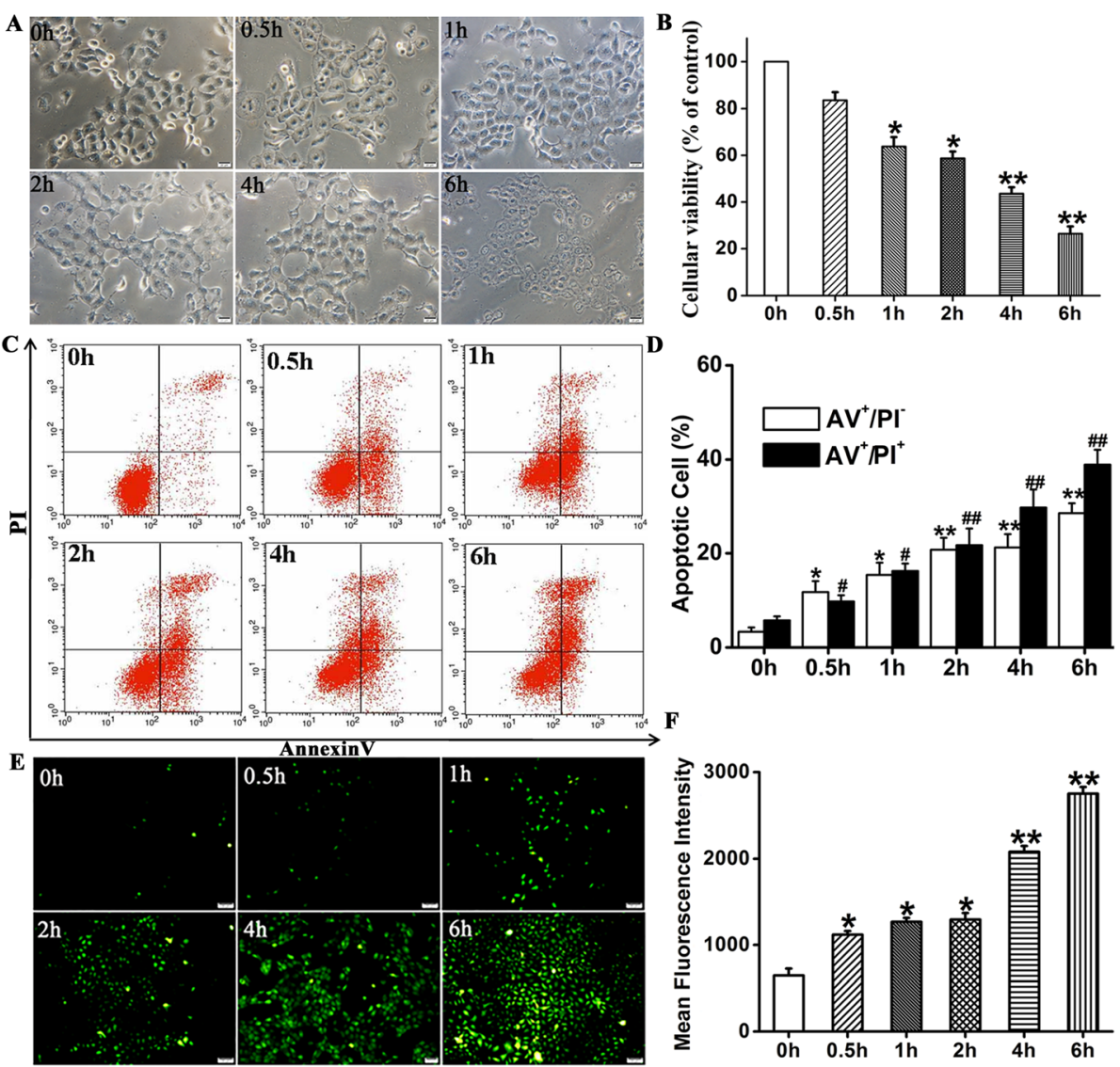

Fig. 2 Effects of $\mathrm{H}_{2} \mathrm{O}_{2}$ on HaCaT according to CCK-8 assay and Annexin V-PI and ROS staining. a Morphological changes in HaCaT cells treated with $1 \mathrm{mM} \mathrm{H}_{2} \mathrm{O}_{2}$ at various times. b HaCaT cells treated with $1 \mathrm{mM} \mathrm{H}_{2} \mathrm{O}_{2}$ at different times followed by viability assay with CCK-8. Histogram shows $\mathrm{H}_{2} \mathrm{O}_{2}$ decreased $\mathrm{HaCaT}$ cell viability in a time-dependent manner. c Annexin V-PI staining combined with flow cytometry assay to detect apoptosis of $\mathrm{HaCaT}$ cells treated with $1 \mathrm{mM} \mathrm{H}_{2} \mathrm{O}_{2}$ at various times. $\mathbf{d}$ Histogram shows that apoptosis increased with induction time. e, $\mathbf{f}$ Analysis of intracellular reactive oxygen species (ROS) levels by DCF-DA assay. Histogram show that fluorescence intensity increased with induction time. Compared to 0 h: ${ }^{*} P<0.05$; ${ }^{\#} P<0.05$. Data are representative of three independent experiments (means \pm SD)

DPQ. Annexin V/PI staining combined with flow cytometry disclosed that $30 \mathrm{mM}$ DPQ significantly reduced $\mathrm{H}_{2} \mathrm{O}_{2}$-induced $\mathrm{HaCaT}$ cell apoptosis. The reductions were $15.23 \pm 2.84 \%$ vs. $29.32 \pm 0.86 \%\left(\mathrm{AV}^{+}\right.$and $\mathrm{PI}^{+} ; P<$ $0.05)$. And $13.45 \pm 2.85 \%$ vs. $23.68 \pm 0.8 \%\left(\mathrm{AV}^{+} / \mathrm{PI}^{-} ; P<\right.$

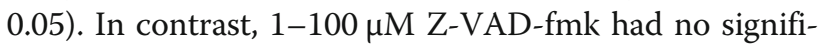
cant protective effects against $\mathrm{H}_{2} \mathrm{O}_{2}$-induced $\mathrm{HaCaT}$ cell apoptosis (Fig. 4a, b).

The western blot assay showed that DPQ pretreatment significantly reduced nuclear AIF and PARP/1 expression in $\mathrm{H}_{2} \mathrm{O}_{2}$-treated $\mathrm{HaCaT}$ cells. However, no significant reduction in mitochondrial AIF expression was observed. In contrast, Z-VAD-fmk pretreatment significantly downregulated mitochondrial AIF but upregulate nuclear AIF and PARP/1 in $\mathrm{H}_{2} \mathrm{O}_{2}$-treated $\mathrm{HaCaT}$ cells. DPQ pretreatment significantly reduced cytosolic PAR accumulation whereas Z-VAD-fmk pretreatment had no significant influence on cytosolic PAR expression in $\mathrm{H}_{2} \mathrm{O}_{2}$-treated $\mathrm{HaCaT}$ cells (Fig. 4c-h).
Fluorescence microscopy revealed that AIF was translocated into the nuclei of $\mathrm{H}_{2} \mathrm{O}_{2}$ - and $\mathrm{H}_{2} \mathrm{O}_{2}+\mathrm{Z}-\mathrm{VAD}$ fmk $\mathrm{HaCaT}$ cells but not into those of the $\mathrm{H}_{2} \mathrm{O}_{2}+\mathrm{DPQ}$ or control $\mathrm{HaCaT}$ cells. PARP/ 1 inhibition by DPQ in $\mathrm{H}_{2} \mathrm{O}_{2}$-induced $\mathrm{HaCaT}$ cells did not downregulate cleaved caspase-3. (Fig. 4i, j).

HucMSC-Ex markedly attenuated $\mathrm{H}_{2} \mathrm{O}_{2}$-induced $\mathrm{HaCaT}$ cell death in a dose- and time-dependent manner

Paracrine factors play important roles in stem cell-based regenerative medicine. To explore the mechanism by which paracrine factors promote cutaneous wound healing, we exposed $\mathrm{HaCaT}$ cells to $\mathrm{H}_{2} \mathrm{O}_{2}$ then cultured them in hucMSCs-CM. The CCK8 assay showed that the viability of the HaCaT cells cultured in hucMSCs$\mathrm{CM}$ was significantly higher than that of the control group $(1.48 \pm 0.04,1.20 \pm 0.05$, and $1.12 \pm 0.02$ relative to the control group at $24 \mathrm{~h}, 48 \mathrm{~h}$, and $72 \mathrm{~h}$, respectively) (Fig. 5a). We derived exosomes from hucMSCs by 


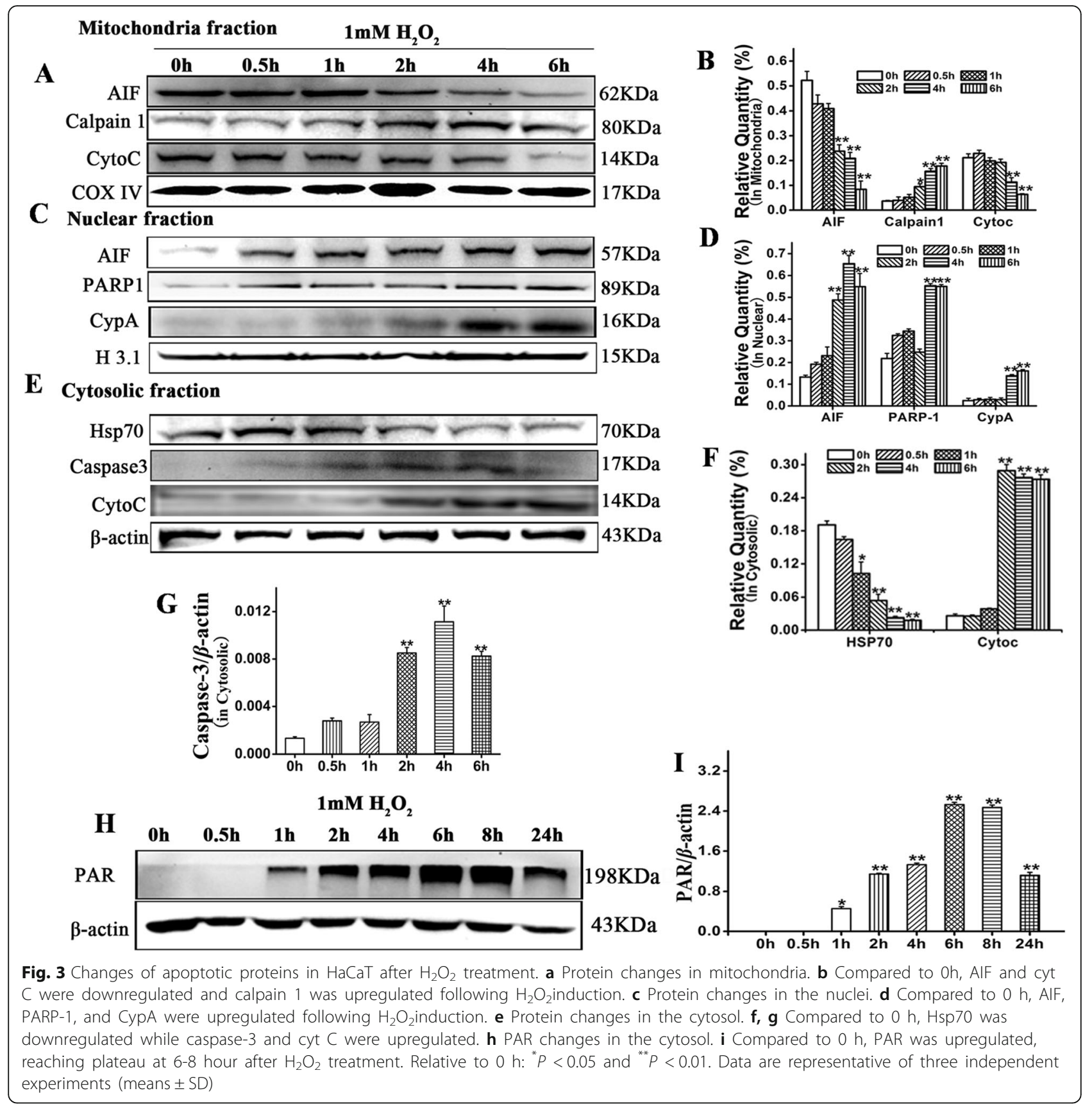

ultracentrifugation and compared their effects on $\mathrm{HaCaT}$ cell proliferation with those of the hucMSCsCM, hucMSCs-dp-Ex, and DMEM/F12 control groups. The hucMSCs-Ex significantly enhanced $\mathrm{HaCaT}$ cell proliferation (control vs. hucMSCs-Ex: 1 vs. $1.69 \pm 0.03$; $P<0.05$ ) as did hucMSCs-CM (control vs. hucMSCs$\mathrm{CM} ; 1$ vs. $1.46 \pm 0.07 ; P<0.05)$. On the other hand, hucMSCs-dp-Ex exhibited no significant efficacy in enhancing $\mathrm{HaCaT}$ cell proliferation $(P>0.05)$ (Fig. $5 \mathrm{~b})$. Moreover, the viability of $\mathrm{HaCaT}$ cells cultured in hucMSCs-Ex increased with a dosage in the range of
$125-1000 \mathrm{ng} \mathrm{mL}^{-1}(0.89 \pm 0.05,0.99 \pm 0.04, \quad 1.15 \pm 0.04$, and $1.48 \pm 0.03$ relative to the control group) (Fig. 5c). Over time, however, the efficacy of hucMSCs-Ex at attenuating $\mathrm{HaCaT}$ cell death decreased, and there was no significant difference from the control after $48 \mathrm{~h}$ (Fig. 5d). Phase-contrast microscopy showed that the cell in the hucMSCs-Ex group is better than $\mathrm{H}_{2} \mathrm{O}_{2}$ group (Fig. 5e). Flow cytometry disclosed that the ROS fluorescence intensity in the hucMSCs-Ex group was significantly lower than that of the $\mathrm{H}_{2} \mathrm{O}_{2}$ group $\left(\mathrm{H}_{2} \mathrm{O}_{2}\right.$ vs. hucMSCs-Ex $2080.44 \pm 68.2$ vs. $567.17 \pm 54.8 ; P<0.01)$. Similar results 

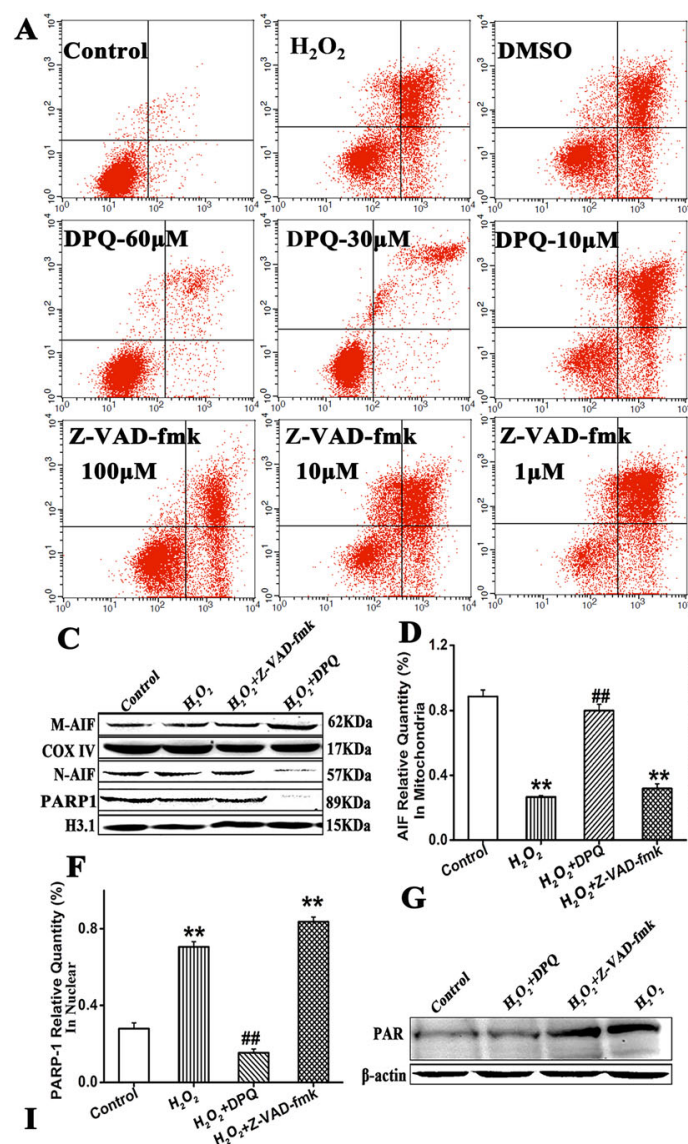

B
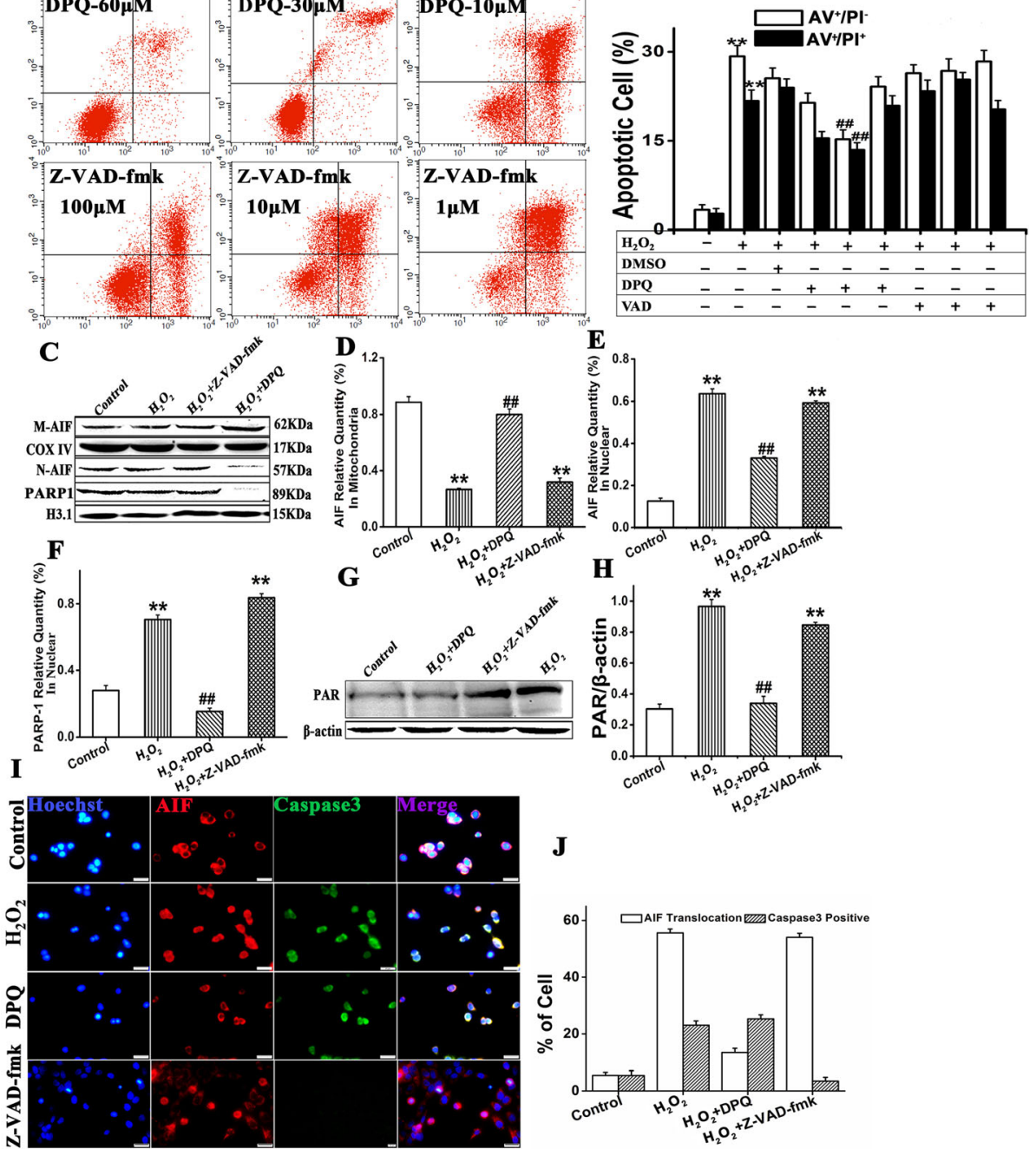

$\mathbf{J}$

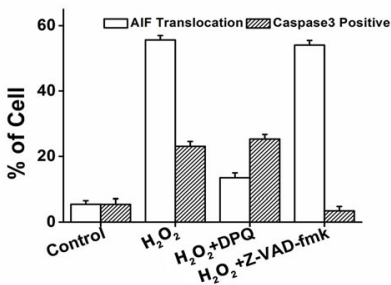

Fig. 4 Caspase inhibitors failed to block AlF translocation in $\mathrm{HaCaT}$ cells treated with $\mathrm{H}_{2} \mathrm{O}_{2}$. a Annexin V-PI combined with flow cytometry was used to detect apoptosis in HaCaT cells treated with DPQ and Z-VAD-fmk. $\mathbf{b}$ Pl- and AnnexinV-positive cells had lower expression levels than the $\mathrm{H}_{2} \mathrm{O}_{2}$ group $\left({ }^{\#} P<0.01\right)$ but not the Z-VAD-fmk treatment. c-f Western blot of AlF translocation by nuclear fractionation in HaCaT cells $4 \mathrm{~h}$ after $\mathrm{H}_{2} \mathrm{O}_{2}$ treatment with $30 \mu \mathrm{M}$ DPQ or $100 \mu \mathrm{M}$ Z-VAD-fmk. Mitochondrial AIF was upregulated in the DPQ group but downregulated in the Z-VADfmk group. Nuclear AIF and PARP-1 were downregulated in the DPQ group. $\mathbf{g}, \mathbf{h}$ PAR in the whole protein was downregulated for the DPQ group but upregulated for the Z-VAD-fmk group. Relative to the control: ${ }^{* *} P<0.01$; compared to $\mathrm{H}_{2} \mathrm{O}_{2}:{ }^{\# \#} P<0.01$. Data are representative of three independent experiments (means \pm SD). $\mathbf{i}, \mathbf{j}$ Fluorescence microscopy of AlF and cleavedcaspase- 3 for the various treatments. Scale bar $=200 \mu m$

were obtained for the hucMSCs-CM group $\left(\mathrm{H}_{2} \mathrm{O}_{2}\right.$ vs. hucMSCs-CM $2080.44 \pm 68.2$ vs. $886.18 \pm 63.98 ; P<$ 0.01) (Fig. 5f, g). The percentage of apoptotic cells for Annexin $\mathrm{V}$-positive cells $\left(\mathrm{AV}^{+} / \mathrm{PI}^{-}\right)$, in the hucMSCs-Ex group was significantly lower than that of the $\mathrm{H}_{2} \mathrm{O}_{2}$ group $\left(\mathrm{H}_{2} \mathrm{O}_{2}\right.$ vs. hucMSCs-Ex $21.23 \pm 2.84$ vs. $4.53 \pm$ 1.07; $P<0.01)$. The percentage of apoptotic cells for Annexin $\mathrm{V}$-and $\mathrm{PI}$ positive cell $\left(\mathrm{AV}^{+}\right.$and $\left.\mathrm{PI}^{+}\right)$, in the
hucMSCs-Ex group significantly reduced (hucMSCs-Ex vs. $\mathrm{H}_{2} \mathrm{O}_{2} 8.67 \pm 2.85$ vs. $\left.29.75 \pm 2.8 ; P<0.05\right)$. This finding was comparable to that determined for the hucMSCs-CM group ( $\mathrm{AV}^{+} / \mathrm{PI}^{-}$cells: $\mathrm{H}_{2} \mathrm{O}_{2}$ vs. hucMSCs$\mathrm{CM} 21.23 \pm 2.84$ vs. $7.25 \pm 2.07 ; \quad P<0.01 ; \quad \mathrm{AV}^{+}$and $\mathrm{PI}^{+}$cells: $\mathrm{H}_{2} \mathrm{O}_{2}$ vs. hucMSCs-CM $29.75 \pm 2.8$ vs. $10.01 \pm$ 2.07; $P<0.01$ (Fig. 5h, i). Nevertheless, neither the ROS fluorescence intensity nor the proportion of apoptotic 


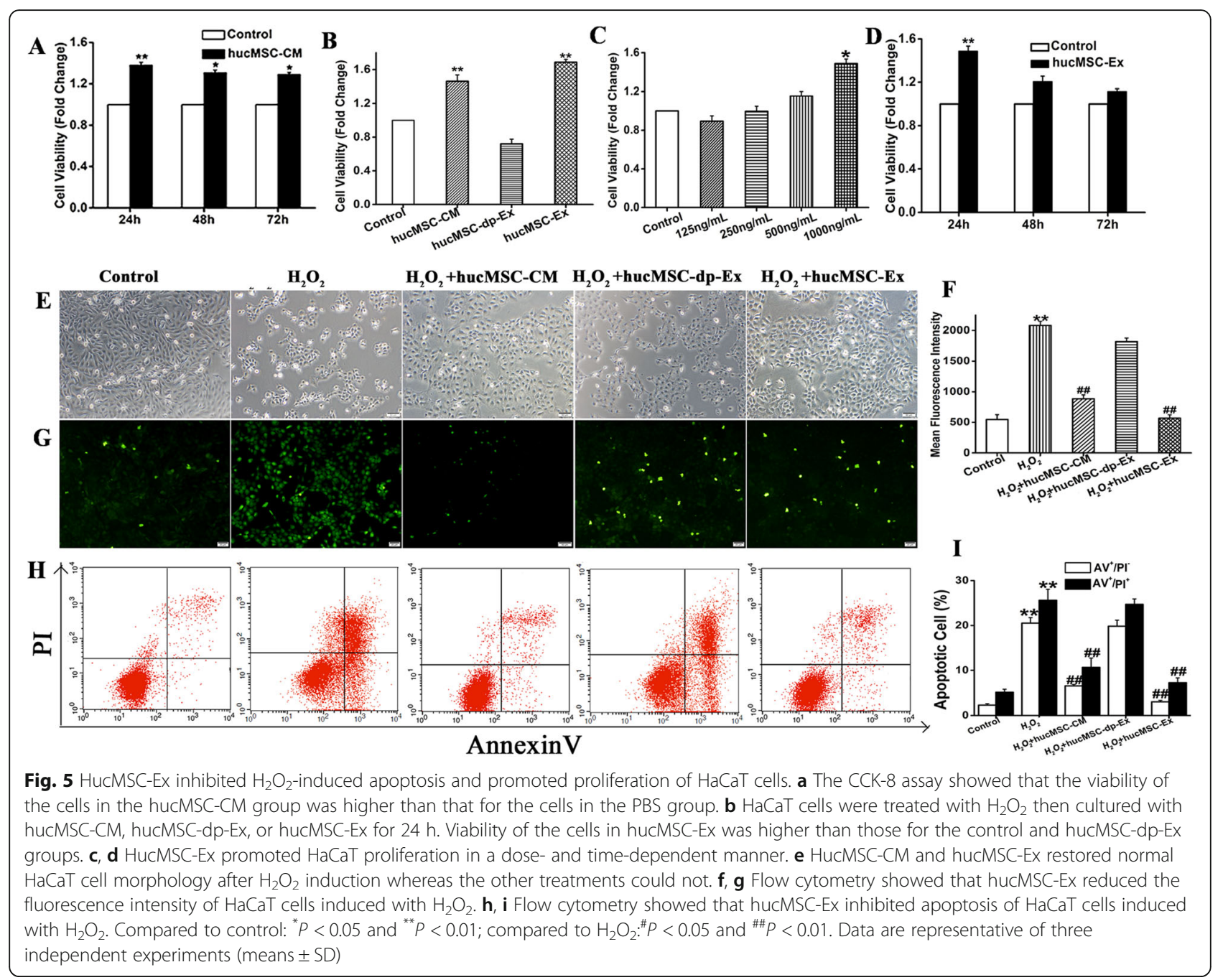

cells significantly differed between the $\mathrm{H}_{2} \mathrm{O}_{2}$ group and the hucMSCs-dp-Ex group $(P>0.05)$.

\section{HucMSC-Ex promoted HaCaT cell migration}

Keratinocyte migration is a critical step in cutaneous wound healing. To explore the effects of hucMSC-Ex on cellular migration, $\mathrm{HaCaT}$ cells were pretreated with $\mathrm{H}_{2} \mathrm{O}_{2}$ then incubated with hucMSC-CM, hucMSC-dp-Ex, or hucMSC-Ex for $24 \mathrm{~h}$. The Transwell assay revealed that incubation with hucMSC-Ex or hucMSC-CM significantly increased the numbers of migrated cells relative to the hucMSC-Ex-dp (3.26 \pm 0.26 (hucMSC-CM) vs. $3.05 \pm 0.22$ (control) $(P<0.05)$; $(4.5 \pm 0.2$ (hucMSC-Ex) vs. $3.05 \pm 0.22$ (control) $(P<0.05) ; 1.9 \pm 0.02$ (hucMSC-Ex-dp) vs. $21 \pm 5.2$ (control) $(P<0.05))$ (Fig. 6a, c). The cell scratching assay showed that the recovery of wound areas of hucMSC-Ex and hucMSC-CM were larger than that for hucMSC-Ex-dp group (62 \pm 6 (hucMSC-CM) vs. $21 \pm 5$ (control) $(P<0.05$ ); $76 \pm 4$ (hucMSC-Ex) vs. $21 \pm 5$ (control) $(P<0.05)$; $35 \pm 6$
(hucMSC-Ex-dp) vs. $21 \pm 5.2$ (control) $(P<0.05))$ (Fig. 6b, d).

HucMSCs-Ex attenuated $\mathrm{H}_{2} \mathrm{O}_{2}$ induces $\mathrm{HaCaT}$ cell death through suppression of AIF nuclear translocation and PARP-1 activation

As our above data showed that $\mathrm{H}_{2} \mathrm{O}_{2}$ induced $\mathrm{HaCaT}$ cell death was mediated by AIF nuclear translocation and PARP activation signals. We would like to know if hucMSC-Ex attenuated $\mathrm{H}_{2} \mathrm{O}_{2}$ induce $\mathrm{HaCaT}$ cell death was through suppression of AIF nuclear translocation and PARP-1 activation or not. Western blot assay showed compared with the control group, $\mathrm{H}_{2} \mathrm{O}_{2}$ insult significantly reduced mitochondrial AIF expression $(P<$ $0.01)$ but increased nuclear AIF and PARP/1 expression $(P<0.01)$. Compared with $\mathrm{H}_{2} \mathrm{O}_{2}$ group, hucMSC-Ex or hucMSCs-CM significantly reduced nuclear AIF and PARP/1 expression $(P<0.01)$. However, similar to $\mathrm{H}_{2} \mathrm{O}_{2}$ group, hucMSCs-dp-CM did not significantly change mitochondrial AIF expression and nuclear AIF and 


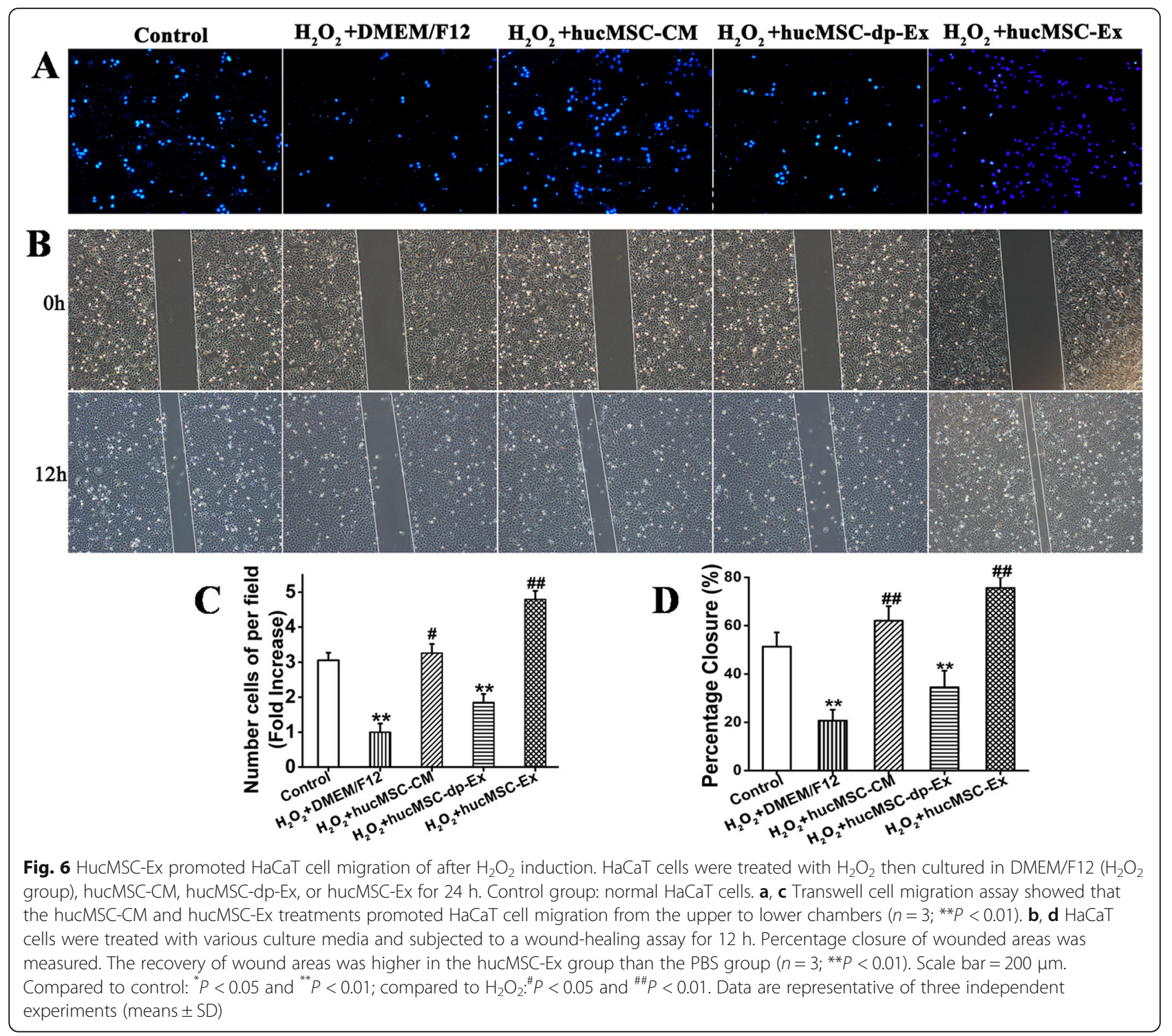

PARP/1 expression (Fig. 7a, b). In addition, $\mathrm{H}_{2} \mathrm{O}_{2}$ insult increased cytosol PAR accumulation and pretreatment with hucMSC-Ex, hucMSCs-CM significantly reduced PAR accumulation in the cytosol in $\mathrm{HaCaT}$ cells $(P<$ 0.01) (Fig. 7c, d).

Tunnel staining showed after treatment with $\mathrm{H}_{2} \mathrm{O}_{2}$, the percentage of tunnel positive cells abruptly increased, significantly higher than the control group $\left(\mathrm{H}_{2} \mathrm{O}_{2}\right.$ vs control, $25.91 \pm 1.21$ vs $5.61 \pm 0.18, P<0.01)$. However, pretreatment of $\mathrm{HaCaT}$ cells with hucMSC-Ex or hucMSCs-CM significantly reduced $\mathrm{H}_{2} \mathrm{O}_{2}$ induced $\mathrm{HaCaT}$ cell death $\left(\mathrm{H}_{2} \mathrm{O}_{2}\right.$ vs hucMSC-Ex, $25.91 \pm 1.21$ vs $4.88 \pm 0.32, P<0.01$; $\mathrm{H}_{2} \mathrm{O}_{2}$ vs hucMSCs-CM, $25.91 \pm 1.21$ vs $6.89 \pm 0.27, P<$ 0.01 ), in contrast to hucMSCs-dp-Ex in that hucMSCsdp-Ex did not show any effects in reducing $\mathrm{H}_{2} \mathrm{O}_{2}$ induced $\mathrm{HaCaT}$ cell death $\left(\mathrm{H}_{2} \mathrm{O}_{2}\right.$ vs hucMSCs-dp-Ex, $25.91 \pm$ 1.21 vs $20.98 \pm 0.42, P>0.05)$. Immune fluorescence staining showed that after treatment with $\mathrm{H}_{2} \mathrm{O}_{2}$, the percentage of nuclear AIF-positive cells abruptly increased, significantly higher than the control group $\left(\mathrm{H}_{2} \mathrm{O}_{2}\right.$ vs control, $43.59 \pm 0.68$ vs $\left.5.96 \pm 0.57\right)$, with remarkable PAR accumulation in the nucleus. However pretreatment with hucMSC-Ex or hucMSCs-CM, the number of nuclear AIF-positive cells abruptly decreased, being significantly lower than the $\mathrm{H}_{2} \mathrm{O}_{2}$ group $\left(\mathrm{H}_{2} \mathrm{O}_{2}\right.$ vs hucMSC-Ex, $43.59 \pm 0.68$ vs $15.23 \pm$ $0.42, P<0.01 . \mathrm{H}_{2} \mathrm{O}_{2}$ vs hucMSCs-CM, $43.59 \pm 0.68$ vs $18.62 \pm 0.41, P<0.01)$ and with less PAR accumulation in the nucleus. In agreement with tunnel staining, hucMSCs-dp-Ex did not show any effects in reducing the percentage of nuclear AIF-positive cells $\left(\mathrm{H}_{2} \mathrm{O}_{2}\right.$ vs hucMSCs-dp-Ex, $43.59 \pm 0.68$ vs $41.05 \pm 0.46, P>0.05$ ) and nuclear PAR accumulation in $\mathrm{H}_{2} \mathrm{O}_{2}$-treated $\mathrm{HaCaT}$ cells (Fig. $7 \mathrm{e}-\mathrm{h}$ ). 


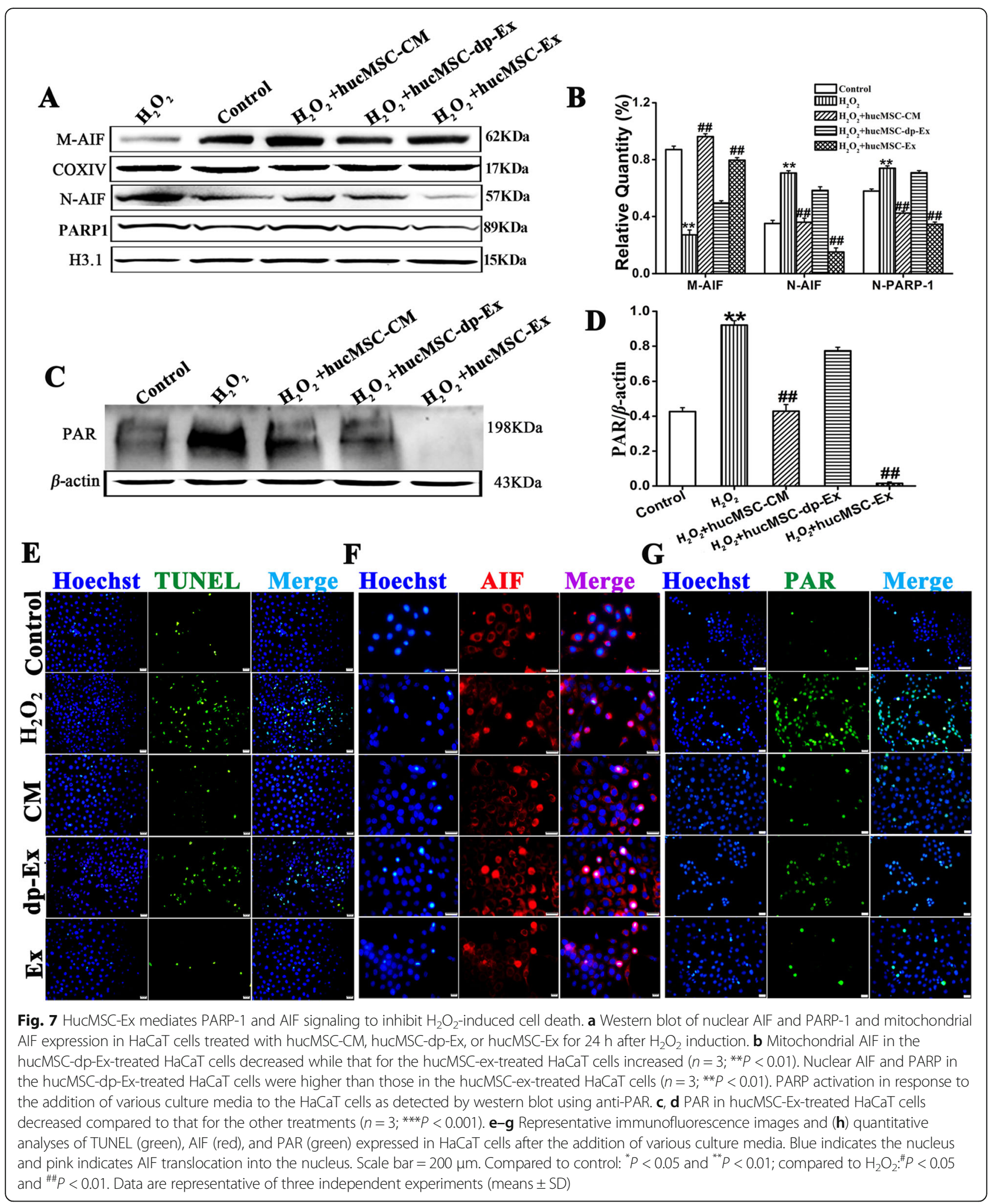




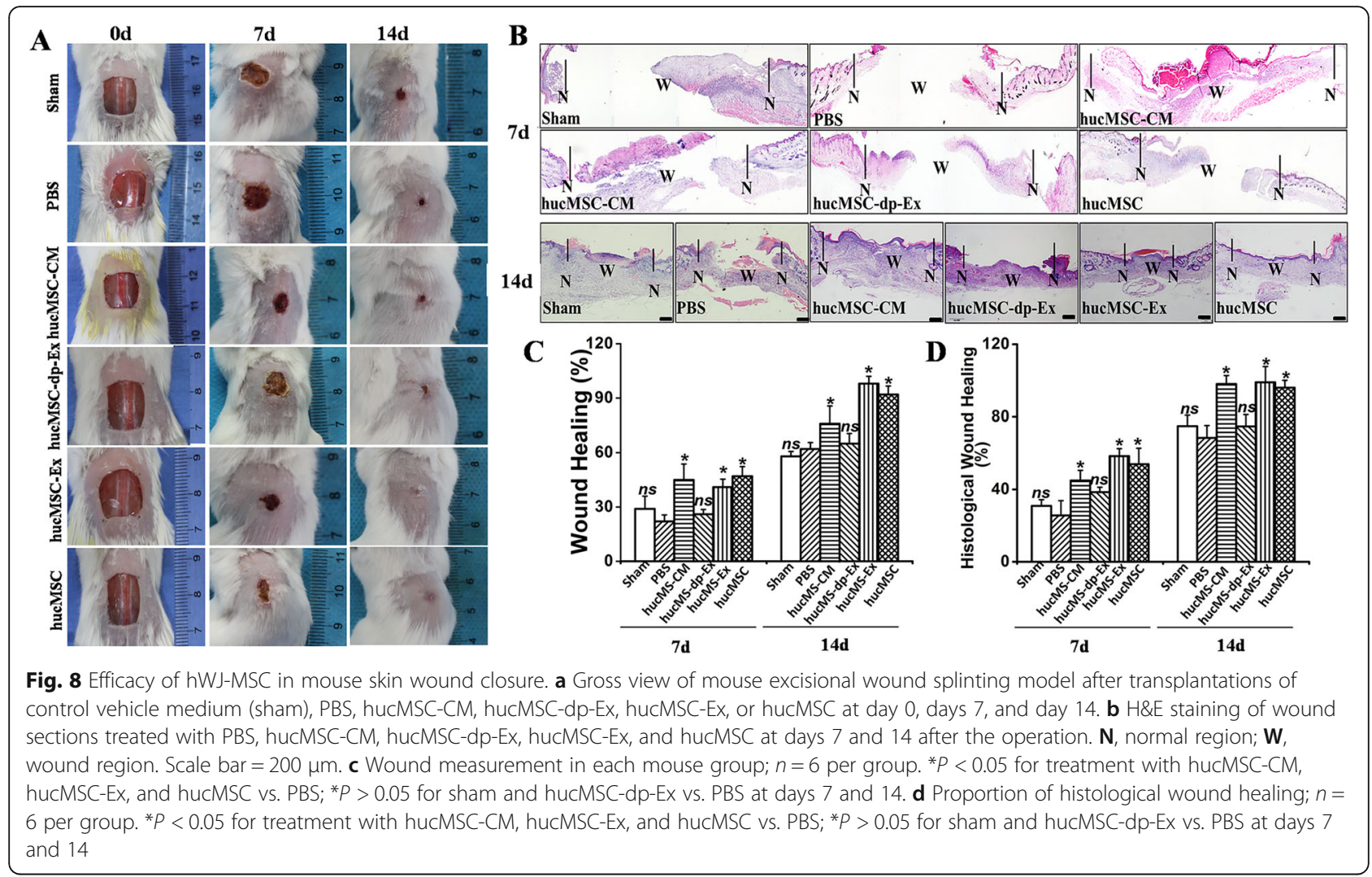

\section{HucMSC-Ex dramatically enhanced cutaneous wound healing, skin barrier formation, and angiogenesis, and reduced scar formation}

To investigate and compare the efficacies of hucMSCEx, hucMSC, hucMSCs-CM, and hucMSCs-dp-CM at enhancing skin wound healing, they were separately injected into excised full-thickness mouse skin. Gross inspection showed that hucMSC-CM, hucMSC-Ex and hucMSC injection significantly increased wound closure at day $7(45.23 \pm 4.8 \%$ (hucMSCs-CM) vs. $22.35 \pm 3.6 \%$ (PBS); $P<0.01 ; 41.12 \pm 5.2 \%$ (hucMSC-Ex) vs. $22.35 \pm$ $3.6 \%$ (PBS); $P<0.01 ; 47.23 \pm 4.9 \%$ (hucMSC) vs. $22.35 \pm$ $3.6 \%$ (PBS), $P<0.01 ; 26.31 \pm 2.3 \%$ (hucMSCs-dp-Ex) vs. $22.35 \pm 3.6 \%$ (PBS), $P>0.01$. At day 14: $76.23 \pm 8.1 \%$ (hucMSCs-CM) vs. $62.41 \pm 2.6 \%$ (PBS), $P<0.05 ; 98.41 \pm$ $1.9 \%$ (hucMSC-Ex) vs. $62.41 \pm 2.6 \% \quad$ (PBS); $P<0.01$; $92.23 \pm 2.6 \%$ (hucMSC) vs. $62.41 \pm 2.6 \%$ (PBS); $P<0.01$; $68.42 \pm 3.5 \%$ (hucMSCs-dp-Ex) vs. $62.41 \pm 2.6 \%$ (PBS); $P>0.01$ (Fig. 8a, c).

H\&E staining indicated that hucMSC-Ex and hucMSC injection significantly enhanced re-epithelialization in the excisional skin wound at day 7 compared to the PBS group. In contrast, the hucMSC-Ex-dp group had no significant effect $(69.1 \pm 4.3 \%$ (hucMSC-Ex) vs. $32.63 \pm 3.5 \%$ (PBS); $57.91 \pm 5.2 \%$ (hucMSC) vs. $32.63 \pm 3.5 \%$ (PBS); $P<0.05 ; 39.3 \pm 2.6 \%$ (hucMSC-Ex-dp) vs. $32.63 \pm 3.5 \%$
(PBS); $P>0.05$. At day 14: $94 \pm 4.2 \%$ (hucMSC-Ex) vs. $75.3 \pm 3.5 \%$ (PBS); $87.91 \pm 5.2 \%$ (hucMSC) vs. $75.3 \pm 3.5 \%$ (PBS); $P<0.05 ; 79.63 \pm 2.6 \%$ (hucMSC-Ex-dp) vs. $75.3 \pm$ 3.5\% (PBS); $P>0.05$ (Fig. 8b, d).

Immunohistological staining showed that hucMSC-Ex and hucMSC injection significantly upregulated CK10, CD31 and downregulated $\alpha$-SMA 14d post-skin wounding (Fig. 9a-e). The optical density for $\alpha$-SMA in the skin wound tissue of the hucMSC-Ex-dp group was significantly higher than those for the hucMSC and hucMSC-Ex groups. Thus, hucMSC-Ex enhanced cutaneous wound healing, re-epithelization, and angiogenesis and reduced scar formation.

\section{Discussion}

In this study, we demonstrated that subcutaneous hucMSC-Ex injection promoted rapid wound closure, re-epithelialization, and new blood vessel formation, and reduced scar formation. Thus, it significantly enhanced skin wound healing.

To explore the mechanism by which hucMSC-Ex stimulated the healing of skin wounds, a skin cell injury model was created by exposing $\mathrm{HaCaT}$ cells to $\mathrm{H}_{2} \mathrm{O}_{2}$. Peroxide induced $\mathrm{HaCaT}$ cell death through mitochondrially mediated caspase-dependent- and caspase-independent apoptosis signaling pathways. Previous reports indicated that 


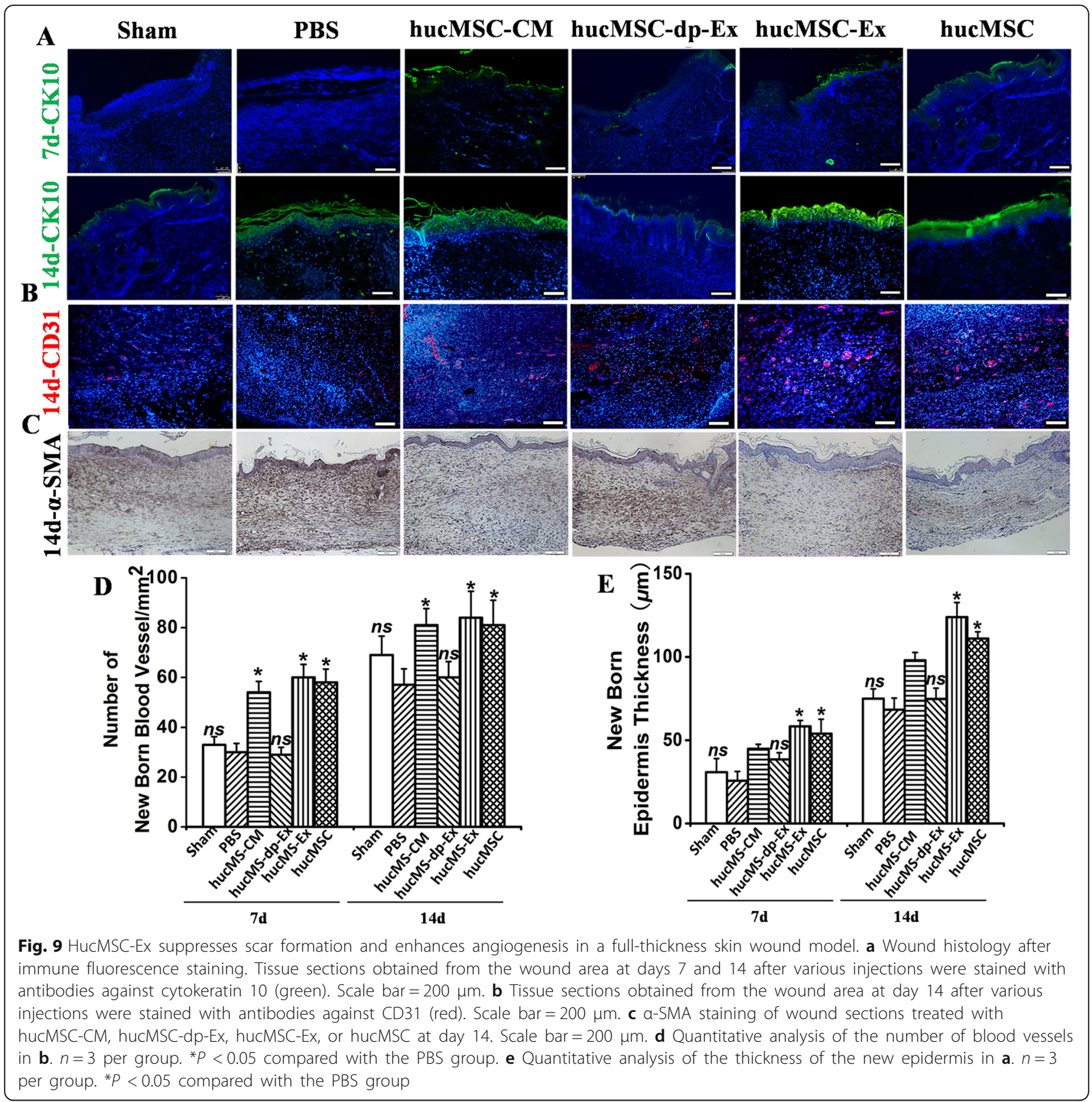

the caspase-independent apoptosis pathway is called PARP-1-dependent cell death or parthanatos [27-29]. It is biochemically distinct from classically defined cell death pathways and comprises rapid PARP-1 activation, early PAR accumulation, mitochondrial depolarization, early nuclear AIF translocation, loss of cellular NAD and ATP, and late caspase activation [30, 31]. $\mathrm{H}_{2} \mathrm{O}_{2}$-induced $\mathrm{HaCaT}$ released ROS which injures DNA and activates PARP-1 $[32,33]$. Our results showed that $\mathrm{H}_{2} \mathrm{O}_{2}$ induced AIF nuclear translocation, PARP-1 hyperactivation, and PAR accumulation. $\mathrm{H}_{2} \mathrm{O}_{2}$ decreases mitochondrial membrane permeability, releases cyt $\mathrm{C}$, activates caspase-3, and stimulates cell apoptosis. When the broad-spectrum caspase inhibitor Z-VAD.fmk and the PARP-1 inhibitor DPQ were added to the $\mathrm{HaCaT}$ cells, the apoptosis rate in the DPQ group was significantly lower than that of the ZVAD.fmk group. Moreover, whereas Z-VAD.fmk could not inhibit AIF translation to the nuclei, DPQ was able to do so. Caspase activation is a hallmark of apoptotic cell death but does not appear to play any role in parthanatos as broad-spectrum caspase inhibitors could not protect the cells $[34,35]$. Thus, $\mathrm{H}_{2} \mathrm{O}_{2}$-induced $\mathrm{HaCaT}$ apoptosis might be mediated via the PARP-1 cell death pathway or parthanatos. 
Over the years, MSC-based therapies [36] have been investigated as a means of augmenting the structure and function of damaged or diseased tissues via direct cell replacement. When MSCs are labeled and delivered in vivo, they migrate to tissue injury sites such as brain lesions and cardiac infarcts [37, 38]. However, relatively few MSCs are actually engrafted at these damage sites and most of them are cleared [39]. Paracrine factors rather than transdifferentiation is now considered the predominant mechanism by which MSCs affect tissue repair. Experiments with MSC-conditioned media demonstrated the importance of the paracrine mechanism of hucMSC in the promotion of wound healing [40, 41]. Our previous study demonstrated that hucMSCs enhance mouse skin wound healing [24].

Exosomes are membrane-bound vesicles produced by MSCs. In cell culture, they are released into the ambient medium. They may be critical messengers for cell-to-cell communication [42]. Studies have shown that stem cellderived exosomes activate resting stem cells in the wound microenvironment by regulating inflammatory and immune responses [43]. In this manner, they proliferate and differentiate into tissue-specific cells, repair damaged tissue cells, promote angiogenesis, improve the local wound microenvironment, and repair and reconstruct tissues. Our results showed that hucMSC-Ex inhibited $\mathrm{H}_{2} \mathrm{O}_{2}$-induced cell death in a time- and dosedependent manner. Other studies reported that hucMSC-Ex inhibited $\mathrm{H}_{2} \mathrm{O}_{2}$-induced cell death by suppressing AIF translation to the nuclei and subsequent PARP-1 hyperactivation [44]. Thus, hucMSC-Ex may mediate a caspase-independent pathway via AIF and PARP-1 to inhibit repair cells such as fibroblasts and keratinocytes in deep apoptosis. In this way, it accelerates cutaneous wound repair and regeneration. We conducted animal tests to determine whether hucMSC-Ex promotes skin wound healing and confirmed by gross inspection and histological observations that it significantly repaired excisional full-thickness defects. The wound healing rate for the hucMSC-Ex group was significantly higher than those for the hucMSC-dp-Ex and PBS groups. Histologically, hucMSC-Ex enhanced skin re-epithelialization. Immunohistological staining was used to elucidate the mechanism by which hucMSC-Ex promotes cutaneous wound healing. CK14, CD31, and $\alpha$-SMA staining disclosed that hucMSC-Ex significantly enhanced skin barrier formation and angiogenesis while dramatically reducing scar formation. CK14 is expressed in the normal epidermis [45]; therefore, its upregulation in the wound after hucMSC-Ex exposure means that the treatment improved the integrity of the newly formed epidermis. Vascular endothelial cells express CD31 [46]; thus, we used it to evaluate the number of newly formed blood vessels in the re-epithelialized tissue following hucMSC-Ex treatment. The $\alpha$-SMA is highly expressed in scar tissue $[47,48]$; for this reason, we applied it to confirm its expression in healing skin. Certain reports demonstrated that MSC-Ex may promote skin wound healing by promoting miR-21-3p-mediated angiogenesis and fibroblast function. Other studies proved that exosomes derived from MSCs enhance skin wound healing by inducing NrF2 [49], MALAT1 [50], or Wnt4 [51] protein factors that mediate cell proliferation, angiogenesis, and migration. Here, however, we showed that hucMSC-Ex inhibits skin cell apoptosis via the PARP-1 pathway and participates in tissue repair and reconstruction.

There were several limitations to the present study. First, it was not established whether it is more advantageous to heal skin wounds by using large volumes of simultaneously injected exosomes or small volumes of exosomes administered over a long period of time. Second, the changes in AIF or PARP-1 expression in wound tissues after hucMSC-Ex transplantation and the mechanism by which AIF/PARP-1 regulates target gene expression were not evaluated in the present study. Third, it was not determined which exosome components regulate the caspase-independent apoptosis pathway in wound healing stimulation. We went further and established the exosomal mechanism of action by tracking exosomal interaction with cells in the real time. We then delved deeper and identified the abundant proteins within the exosomes cargo using a proteomics approach and to look for the key protein for wound healing.

In summary, our research indicated that hucMSC-Ex effectively enhances cutaneous wound healing in mice possibly by $\mathrm{HaCaT}$ cell activation in the skin. The hucMSC-Ex promoted $\mathrm{HaCaT}$ cell proliferation and migration and inhibited $\mathrm{H}_{2} \mathrm{O}_{2}$-induced $\mathrm{HaCaT}$ cell death in vitro. In hucMSC-Ex-dependent regulation of $\mathrm{HaCaT}$ cell function, the caspase-independent PARP-1 and AIF apoptosis pathway play vital roles as hucMSC-Ex markedly reduces AIF translocation and PARP-1 hyperactivation. Our findings suggest that hucMSC-Ex is a new therapeutic tool for tissue wound healing by inhibiting deep apoptosis of repair cells. Next, maybe we will choose the big animals, such as pig, to experiment that whether the hucMSCs-Ex can also enhance diabetic skin wound healing. After elucidating the mechanism of hucMSCs-Ex for tissue repair, it may contribute to the treatment of clinical patient-related diseases in the future.

\section{Conclusion}

The hucMSc-Ex effectively enhances cutaneous wound healing possibly by activating $\mathrm{HaCaT}$ cells in the skin. HucMSC-Ex promotes $\mathrm{HaCaT}$ cell proliferation and 
migration, and inhibits $\mathrm{H}_{2} \mathrm{O}_{2}$-induced $\mathrm{HaCaT}$ cell apoptosis in vitro via a caspase-independent pathway in which PARP-1 activation signals AIF release from the mitochondria to the nuclei.

\begin{abstract}
Abbreviations
AIF: Apoptosis-inducing factor; BSA: Bovine serum albumin; cyt C: Cytochrome C; DMEM: Dulbecco's modified Eagle's medium; DMSO: Dimethylsulfoxide; FBS: Fetal bovine serum; GAPDH: Glyceraldehyde3-phosphate dehydrogenase; $\mathrm{H} \& \mathrm{E}$ : Hematoxylin and eosin; $\mathrm{H}_{2} \mathrm{O}_{2}$ : Hydrogen peroxide; HaCaT: Immortalized human keratinocytes; HRP: Horseradish peroxidase; hucMSC: Human umbilical cord mesenchymal stem cells; hucMSC-CM: HucMSC-derived conditioned medium; hucMSC-dpEx: Exosomes-deprived hucMSCs-conditioned media; hucMSC-Ex: HucMSCsderived exosomes; hucMSCs: Human umbilical cord mesenchymal stem cells; MSC: Mesenchymal stem cells; PAR: Poly (ADP-ribose); PARP-1: Poly (ADPribose) polymerase-1; PMSF: Phenylmethylsulfonyl fluoride
\end{abstract}

\section{Acknowledgements}

The authors would like to thank all members of both departments for their kind comments.

\section{Authors' contributions}

$\mathrm{GZ}$ and FL contribute equally to this paper. GZ performed the in vitro assays and data analysis and interpretation and drafted the manuscript. FL and KZ performed the hucMSC isolation and characterization by flow cytometry and immunohistochemical analyses. ZL acquired, analyzed, and interpreted the data. XH and YZ isolated and characterized the hucMSC-EX. BW and AL conducted molecular biology studies. YW and FZ designed the experiments and performed the statistical analysis. ML and XL analyzed and interpreted the data. MJ and GL did the animal experiment. JL designed, coordinated, and modified the article the manuscript. All authors read and approved the final draft of the manuscript

\section{Funding}

This work was supported by the China Natural National Science Foundation (81573067 and 81901972), the Joint construction project between Jilin province and provincial colleges (SXGJQY2017-12), the Jilin Province Science and Technology Development Plan (20190304044YY), the Innovative special industry fund project in Jilin province (2018C049-2), and the Open Research Project of the State Key Laboratory of Industrial Control Technology, Zhejiang University, China (ICT1800381), Jilin Province Department of Education (no. JJKH20191063KJ), Jilin City Science and Technology Innovation Development Plan Project (201831745), and Jilin Medical College Doctoral Research Foundation Project (JYBS2018011). We would like to thank Editage [www.editage.cn] for English language editing.

\section{Availability of data and materials}

All data generated or analyzed during this study are included in this published article.

\section{Ethics approval and consent to participate}

This study was approved by the Ethical/Scientific Committee of Jilin University.

\section{Consent for publication}

Not applicable.

\section{Competing interests}

The authors declare that they have no competing interests.

\section{Author details}

'Department of Toxicology, School of Public Health, Jilin University, No. 1163 Xinmin Street, Changchun, Jilin 130021, China. ${ }^{2}$ Department of Pathology, Jilin Medical University, Jilin, China. ${ }^{3}$ Department of Ophthalmology, the Second Hospital of Jilin University, Changchun, China.
Received: 3 November 2019 Revised: 2 February 2020

Accepted: 24 February 2020 Published online: 11 May 2020

\section{References}

1. Nour S, Baheiraei N, Imani R, Khodaei M, Alizadeh A, Rabiee N, Moazzeni SM. A review of accelerated wound healing approaches: biomaterial- assisted tissue remodeling. J Materials Sci Materials Med. 2019;30(10):120.

2. Li JY, Ren KK, Zhang WJ, Xiao L, Wu HY, Liu QY, Ding T, Zhang XC, Nie WJ Ke $Y$, et al. Human amniotic mesenchymal stem cells and their paracrine factors promote wound healing by inhibiting heat stress-induced skin cell apoptosis and enhancing their proliferation through activating PI3K/AKT signaling pathway. Stem Cell Res Ther. 2019;10(1):247.

3. Schafer M, Werner S. Oxidative stress in normal and impaired wound repair. Pharmacol Res. 2008;58(2):165-71.

4. Yang $C T$, Chen L, Chen WL, Li N, Chen MJ, Li X, Zheng X, Zhao YZ, Wu YX, Xian $M$, et al. Hydrogen sulfide primes diabetic wound to close through inhibition of NETosis. Mol Cell Endocrinol. 2019;480:74-82.

5. Goodarzi P, Falahzadeh K, Nematizadeh M, Farazandeh P, Payab M, Larijani B, Tayanloo Beik A, Arjmand B. Tissue engineered skin substitutes. Adv Exp Med Biol. 2018:1107:143-88.

6. Kreimendahl F, Marquardt Y, Apel C, Bartneck M, Zwadlo-Klarwasser G, Hepp J, Jockenhoevel S, Baron JM. Macrophages significantly enhance wound healing in a vascularized skin model. J Biomed Mater Res A. 2019;107(6): 1340-50.

7. Wolak M, Staszewska T, Juszczak M, Galdyszynska M, Bojanowska E. Antiinflammatory and pro-healing impacts of exendin-4 treatment in Zucker diabetic rats: effects on skin wound fibroblasts. Eur J Pharmacol. 2019;842: 262-9.

8. Costa R, Negrao R, Valente I, Castela A, Duarte D, Guardao L, Magalhaes PJ, Rodrigues JA, Guimaraes JT, Gomes P, et al. Xanthohumol modulates inflammation, oxidative stress, and angiogenesis in type 1 diabetic rat skin wound healing. J Nat Prod. 2013;76(11):2047-53.

9. Shao $Y$, Dang M, Lin Y, Xue F. Evaluation of wound healing activity of plumbagin in diabetic rats. Life Sci. 2019;231:116422.

10. Al-Eidi S, Tayel S, Al-Slail F, Qureshi NA, Sohaibani I, Khalil M, Al-Bedah AM Knowledge, attitude and practice of patients with type 2 diabetes mellitus towards complementary and alternative medicine. J Integrative Med. 2016; 14(3):187-96.

11. Cong X, Zhang SM, Batty L, Luo J. Application of human induced pluripotent stem cells in generating tissue engineered blood vessels as vascular grafts. Stem Cells Dev. 2019;28(24):1581-94.

12. de Vries DK, Schaapherder AF, Reinders ME. Mesenchymal stromal cells in renal ischemia/reperfusion injury. Front Immunol. 2012;3:162.

13. Rodriguez-Menocal L, Salgado M, Ford D, Van Badiavas E. Stimulation of skin and wound fibroblast migration by mesenchymal stem cells derived from normal donors and chronic wound patients. Stem Cells Transl Med. 2012; 1(3):221-9.

14. Boelens MC, Wu TJ, Nabet BY, Xu B, Qiu Y, Yoon T, Azzam DJ, Twyman-Saint Victor C, Wiemann BZ, Ishwaran $\mathrm{H}$, et al. Exosome transfer from stromal to breast cancer cells regulates therapy resistance pathways. Cell. 2014;159(3): 499-513.

15. Guo J, Cheng P, Yuan H, Liu Y. The exosome regulates circadian gene expression in a posttranscriptional negative feedback loop. Cell. 2009;138(6): 1236-46.

16. Nabet BY, Qiu Y, Shabason JE, Wu TJ, Yoon T, Kim BC, Benci JL, DeMichele AM, Tchou J, Marcotrigiano J, et al. Exosome RNA Unshielding couples stromal activation to pattern recognition receptor signaling in Cancer. Cell. 2017;170(2):352-66 e313.

17. Xu R, Zhang F, Chai R, Zhou W, Hu M, Liu B, Chen X, Liu M, Xu Q, Liu N et al. Exosomes derived from pro-inflammatory bone marrow-derived mesenchymal stem cells reduce inflammation and myocardial injury via mediating macrophage polarization. J Cell Mol Med. 2019;23(11):7617-31.

18. Li JJ, Hosseini-Beheshti E, Grau GE, Zreiqat H, Little CB: Stem cell-derived extracellular vesicles for treating joint injury and osteoarthritis. Nanomaterials. 2019:9(2):261

19. Fatima F, Nawaz M. Stem cell-derived exosomes: roles in stromal remodeling, tumor progression, and cancer immunotherapy. Chinese J Cancer. 2015;34(12):541-53.

20. Liu Y, Luo F, Wang B, Li H, Xu Y, Liu X, Shi L, Lu X, Xu W, Lu L, et al. STAT3regulated exosomal miR-21 promotes angiogenesis and is involved in 
neoplastic processes of transformed human bronchial epithelial cells. Cancer Lett. 2016;370(1):125-35.

21. Ribeiro-Rodrigues $T M$, Laundos $T L$, Pereira-Carvalho $R$, Batista-Almeida $D_{\text {, }}$ Pereira R, Coelho-Santos V, Silva AP, Fernandes R, Zuzarte M, Enguita FJ, et al. Exosomes secreted by cardiomyocytes subjected to ischaemia promote cardiac angiogenesis. Cardiovasc Res. 2017;113(11):1338-50.

22. Zhao L, Johnson T, Liu D. Therapeutic angiogenesis of adipose-derived stem cells for ischemic diseases. Stem Cell Res Ther. 2017:8(1):125.

23. Svensson KJ, Christianson HC, Wittrup A, Bourseau-Guilmain E, Lindqvist E, Svensson LM, Morgelin M, Belting M. Exosome uptake depends on ERK1/2heat shock protein 27 signaling and lipid raft-mediated endocytosis negatively regulated by caveolin-1. J Biol Chem. 2013;288(24):17713-24.

24. Zhao G, Liu F, Lan S, Li P, Wang L, Kou J, Qi X, Fan R, Hao D, Wu C, et al. Large-scale expansion of Wharton's jelly-derived mesenchymal stem cells on gelatin microbeads, with retention of self-renewal and multipotency characteristics and the capacity for enhancing skin wound healing. Stem Cell Res Ther. 2015;6:38.

25. Hu GW, Li Q, Niu X, Hu B, Liu J, Zhou SM, Guo SC, Lang HL, Zhang $\mathrm{CQ}$, Wang $\mathrm{Y}$, et al. Exosomes secreted by human-induced pluripotent stem cell-derived mesenchymal stem cells attenuate limb ischemia by promoting angiogenesis in mice. Stem Cell Res Therapy. 2015;6:10.

26. Zhang W, Yang J, Cao D, You Y, Shen K, Peng P. Regulation of exosomes released from normal ovarian epithelial cells and ovarian cancer cells. Tumour Biol. 2016;37(6):15763-71.

27. Aredia F, Scovassi Al. Poly (ADP-ribose): a signaling molecule in different paradigms of cell death. Biochem Pharmacol. 2014;92(1):157-63.

28. Aredia F, Scovassi Al. Involvement of PARPs in cell death. Front Biosci. 2014; 6:308-17.

29. Basello DA, Scovassi Al. Poly (ADP-ribosylation) and neurodegenerative disorders. Mitochondrion. 2015;24:56-63.

30. Zheng $T$, Zheng $C Y$, Zheng $X C$, Zhao RG, Chen YQ. Effect of parthanatos on ropivacaine-induced damage in SH-SY5Y cells. Clin Exp Pharmacol Physiol. 2017:44(5):586-94.

31. Jiang HY, Yang Y, Zhang YY, Xie Z, Zhao XY, Sun Y, Kong WJ. The dual role of poly (ADP-ribose) polymerase-1 in modulating parthanatos and autophagy under oxidative stress in rat cochlear marginal cells of the stria vascularis. Redox Biol. 2018:14:361-70.

32. Chang H, Sander CS, Muller CS, Elsner P, Thiele JJ. Detection of poly (ADPribose) by immunocytochemistry: a sensitive new method for the early identification of UVB- and H2O2-induced apoptosis in keratinocytes. Biol Chem. 2002;383(3-4):703-8

33. Lee $H$, Yeom M, Shin S, Jeon K, Park D, Jung E. Protective effects of aqueous extract of Mentha suaveolens against oxidative stress-induced damages in human keratinocyte $\mathrm{HaCaT}$ cells. Evidence-Based Complementary Alternative Med. 2019;2019:5045491

34. Yang X, Wang S, Lin Y, Han Y, Qiu X, Zhao X, Cao L, Wang X, Chi Z. Poly (ADP-ribose) polymerase inhibition protects epileptic hippocampal neurons from apoptosis via suppressing Akt-mediated apoptosis-inducing factor translocation in vitro. Neuroscience. 2013;231:353-62.

35. Zhao L, Lin H, Chen S, Chen S, Cui M, Shi D, Wang B, Ma K, Shao Z. Hydrogen peroxide induces programmed necrosis in rat nucleus pulposus cells through the RIP1/RIP3-PARP-AIF pathway. J Orthopaedic Res. 2018; 36(4):1269-82

36. Paulini J, Higuti E, Bastos RM, Gomes SA, Rangel EB. Mesenchymal stem cells as therapeutic candidates for halting the progression of diabetic nephropathy. Stem Cells Int. 2016;2016:9521629.

37. Huang B, Tabata Y, Gao JQ. Mesenchymal stem cells as therapeutic agents and potential targeted gene delivery vehicle for brain diseases. J Controlled Release. 2012;162(2):464-73.

38. de Almeida FM, Marques SA, Ramalho Bdos S, Massoto TB, Martinez AM. Chronic spinal cord lesions respond positively to tranplants of mesenchymal stem cells. Restor Neurol Neurosci. 2015;33(1):43-55.

39. Ullah M, Liu DD, Thakor AS. Mesenchymal Stromal Cell Homing: Mechanisms and Strategies for Improvement. iscience. 2019;15:421-38.

40. Bak DH, Choi MJ, Kim SR, Lee BC, Kim JM, Jeon ES, Oh W, Lim ES, Park BC, Kim MJ, et al. Human umbilical cord blood mesenchymal stem cells engineered to overexpress growth factors accelerate outcomes in hair growth. Korean J Physiol Pharmacol. 2018;22(5):555-66.

41. Meng SS, Guo FM, Zhang XW, Chang W, Peng F, Qiu HB, Yang Y. mTOR/ STAT-3 pathway mediates mesenchymal stem cell-secreted hepatocyte growth factor protective effects against lipopolysaccharide-induced vascular endothelial barrier dysfunction and apoptosis. J Cell Biochem. 2019;120(3): $3637-50$.

42. Yuan QL, Zhang YG, Chen Q. Mesenchymal stem cell (MSC)-derived extracellular vesicles: potential therapeutics as MSC trophic mediators in regenerative medicine. Anat Rec. 2019. PMID:31168963. https://doi.org/10. 1002/ar.24186.

43. Fatima F, Ekstrom K, Nazarenko I, Maugeri M, Valadi H, Hill AF, Camussi G, Nawaz M. Non-coding RNAs in mesenchymal stem cell-derived extracellular vesicles: deciphering regulatory roles in stem cell potency, inflammatory resolve, and tissue regeneration. Front Genet. 2017:8:161.

44. Wenz C, Faust D, Linz B, Turmann C, Nikolova T, Bertin J, Gough P, Wipf P, Schroder AS, Krautwald $\mathrm{S}$, et al. T-BuOOH induces ferroptosis in human and murine cell lines. Arch Toxicol. 2018;92(2):759-75.

45. Jorgensen E, Lazzarini G, Pirone A, Jacobsen S, Miragliotta V. Normal microscopic anatomy of equine body and limb skin: a morphological and immunohistochemical study. Annals Anatomy. 2018;218:205-12.

46. Hartwell R, Poormasjedi-Meibod MS, Chavez-Munoz C, Jalili RB, Hossenini-Tabatabaei A, Ghahary A. An in-situ forming skin substitute improves healing outcome in a hypertrophic scar model. Tissue Eng A. 2015;21(5-6):1085-94

47. Zhang Z, Garron T, Li XJ, Liu Y, Zhang X, Li YY, Xu WS. Recombinant human Decorin inhibits TGF-b1 induced contraction of collagen lattice by keloid fibroblasts. Wounds. 2009:21(2):47-56.

48. Li Q, Zhao H, Chen W, Huang P, Bi J. Human keratinocyte-derived microvesicle miRNA-21 promotes skin wound healing in diabetic rats through facilitating fibroblast function and angiogenesis. Int J Biochem Cell Biol. 2019;114:105570.

49. Li X, Xie X, Lian W, Shi R, Han S, Zhang H, Lu L, Li M. Exosomes from adipose-derived stem cells overexpressing Nrf2 accelerate cutaneous wound healing by promoting vascularization in a diabetic foot ulcer rat model. Exp Mol Med. 2018;50(4):29.

50. Dai X, Chen C, Xue J, Xiao T, Mostofa G, Wang D, Chen X, Xu H, Sun Q, Li J, et al. Exosomal MALAT1 derived from hepatic cells is involved in the activation of hepatic stellate cells via miRNA-26b in fibrosis induced by arsenite. Toxicol Lett. 2019;316:73-84.

51. Huang Z, Yang M, Li Y, Yang F, Feng Y. Exosomes derived from hypoxic colorectal cancer cells transfer Wnt4 to normoxic cells to elicit a prometastatic phenotype. Int J Biol Sci. 2018;14(14):2094-102.

\section{Publisher's Note}

Springer Nature remains neutral with regard to jurisdictional claims in published maps and institutional affiliations.
Ready to submit your research? Choose BMC and benefit from:
- fast, convenient online submission
- thorough peer review by experienced researchers in your field
- rapid publication on acceptance
- support for research data, including large and complex data types
- gold Open Access which fosters wider collaboration and increased citations
- maximum visibility for your research: over $100 \mathrm{M}$ website views per year
At $\mathrm{BMC}$, research is always in progress.
Learn more biomedcentral.com/submission 